\title{
Carbon Encapsulated Heazlewoodite Nanoparticles as Highly Efficient and Durable Electrocatalysts for Oxygen Evolution Reactions
}

TABLE OF CONTENTS (TOC) Carbon Encapsulated Heazlewoodite Nanoparticles as Highly
Efficient and Durable Electrocatalysts for Oxygen Evolution Reactions

Mohammad Al-Mamun ${ }^{1}$, Huajie Yin ${ }^{1}$, Porun Liu ${ }^{1}$, Xintai $\mathrm{Su}^{1,2}$, Haimin Zhang ${ }^{3}$, Huagui Yang ${ }^{1}$, Dan Wang ${ }^{1}$, Zhiyong Tang ${ }^{1}$, Yun Wang $^{1}$, Huijun Zhao ${ }^{1,3 *}$

${ }^{1}$ Centre for Clean Environment and Energy, Griffith University, Gold Coast Campus, QLD 4222, Australia

${ }^{2}$ Ministry Key Laboratory of Oil and Gas Fine Chemicals, College of Chemistry and Chemical Engineering, Xinjiang University, Urumqi 830046, China.

${ }^{3}$ Centre for Environmental and Energy Nanomaterials, Institute of Solid State Physics, Chinese Academy of Sciences, Hefei 230031, China.

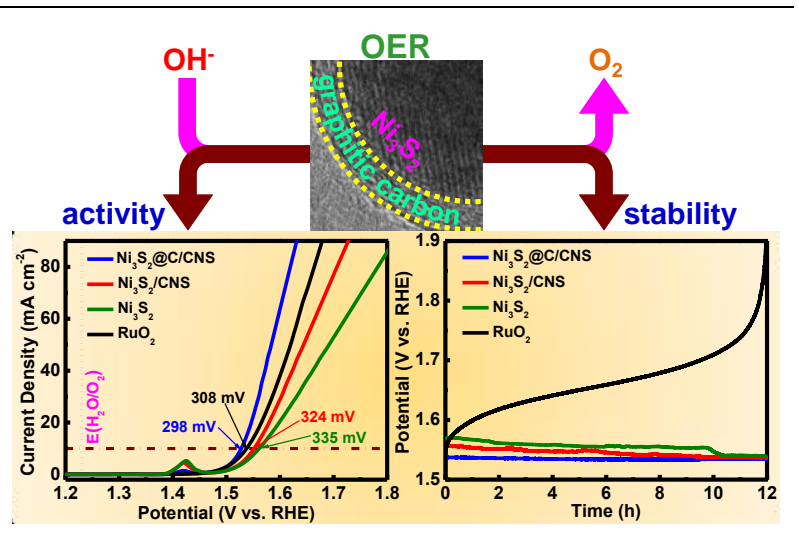

Carbon encapsulation improves the activity and stability of heazlewoodite nanoparticles as oxygen evolution electrocatalysts.

Page Numbers. The font is

ArialMT 16 (automatically inserted by the publisher) 
Nano Res

DOI (automatically inserted by the publisher)

Research Article

\title{
Carbon Encapsulated Heazlewoodite Nanoparticles as Highly Efficient and Durable Electrocatalysts for Oxygen Evolution Reactions
}

\author{
Mohammad Al-Mamun', Huajie Yin', Porun Liu', Xintai Su, ${ }^{1,2}$, Haimin Zhang ${ }^{3}$, Huagui Yang', Dan Wang', \\ Zhiyong Tang ${ }^{1}$, Yun Wang $(\bowtie)$, Huijun Zhao ${ }^{1,3}(\bowtie)$ \\ ${ }^{1}$ Centre for Clean Environment and Energy, Griffith University, Gold Coast Campus QLD 4222, Australia \\ ${ }^{2}$ Ministry Key Laboratory of Oil and Gas Fine Chemicals, College of Chemistry and Chemical Engineering, Xinjiang University, \\ Urumqi 830046, China \\ ${ }^{3}$ Centre for Environmental and Energy Nanomaterials, Institute of Solid State Physics, Chinese Academy of Sciences, Hefei 230031, \\ China
}

Received: day month year / Revised: day month year / Accepted: day month year (automatically inserted by the publisher) (C) Tsinghua University Press and Springer-Verlag Berlin Heidelberg 2011

\begin{abstract}
The activity and durability of electrocatalysts are two of the most important factors for their practical applications, such as the electrocatalytic oxygen evolution reactions (OERs) used in water splitting cells and metal-air batteries. In this study, a novel electrocatalyst, few-layered graphitic carbon $(\sim 5$ atomic layers $)$ encapsulated heazlewoodite ( $\left.\mathrm{Ni}_{3} \mathrm{~S}_{2} @ \mathrm{C}\right)$ nanoparticles (NPs), was purposely designed and experimentally synthesised via one-step solid phase pyrolysis method. In the OER test, the $\mathrm{Ni}_{3} \mathrm{~S}_{2} @ \mathrm{C}$ catalyst exhibited an overpotential of $298 \mathrm{mV}$ at current density of $10 \mathrm{~mA} \mathrm{~cm}^{-2}$, Tafel slope of $51.3 \mathrm{mV} \mathrm{dec}^{-1}$, and charge transfer resistance of $22.0 \Omega$, which are better than those of benchmark $\mathrm{RuO}_{2}$ and most other nickel sulfide-based catalysts reported to date. The improved performance can be ascribed to the high electronic conductivity of graphitic carbon encapsulating layers. Moreover, the encapsulation of graphitic carbon layers provides superb stability without any noticeable oxidation or depletion of $\mathrm{Ni}_{3} \mathrm{~S}_{2} \mathrm{NPs}$ within the nanocomposite. The strategy introduced in this work can, therefore, benefit the development of highly stable metal sulfide electrocatalysts without sacrificing the electrocatalytic activity for energy conversion and storage applications.
\end{abstract}

\section{KEYWORDS}

heazlewoodite, electrocatalysts, encapsulation, oxygen evolution reaction, pyrolysis, graphitic carbon

\section{Introduction}

The oxygen evolution reaction (OER) is recognised as a key half reaction in many electrochemical applications and devices such as solar water splitting [1], water electrolysis cells [2] and recently, metal-air batteries as a charging reaction [3]. However, the thermodynamically unfavourable and kinetically sluggish OER process requires precious 
metal-based catalysts, e.g. $\mathrm{RuO}_{2}$ and $\mathrm{IrO}_{2}$, to reduce the overpotential and thereby achieve a current density of $10 \mathrm{~mA} \mathrm{~cm}^{-2}$, the metric relevant to solar fuel synthesis [4-7]. But the elemental scarcity and high-cost of such noble metal-based electrocatalysts considerably impede the widespread utilisation of these catalysts. Therefore, the development of highly efficient and earth-abundant electrocatalysts for OERs is of paramount significance in designing efficient and affordable energy conversion and storage devices.

In particular, transition metal sulfides have attracted considerable attention as a promising but less investigated class of OER electrocatalysts [8-10]. The Ni metal rich heazlewoodite $\left(\mathrm{Ni}_{3} \mathrm{~S}_{2}\right)$ has recently shown desired electrocatalytic behaviour for either oxygen reduction reactions (ORRs) [11], hydrogen evolution reactions (HERs) [12, 13] or OERs [14-17]. However, most transition metal sulfides experience serious oxidation at the high anodic potential required for OER catalysis [8, 18-21]. This unavoidable electrochemical phenomenon hinders the inherent OER activity evaluation and it can also affect the long-term electrocatalytic stability of the catalysts.

One feasible way of minimising the possibility of such oxidation processes, while maintaining reasonable electrocatalytic activity, is to encapsulate the metal sulfide nanoparticles (NPs) with an ultrathin layer of foreign substances. Recently, this strategy has been demonstrated to be potentially advantageous in maintaining the parent structural and chemical integrity of the metal based materials in many electrochemical processes [22-27]. And graphitic carbon is one of the best candidates to achieve this goal as it possesses high electronic conductivity and considerable electrochemical inertness [28]. Moreover, Bao and his co-workers discovered that the interaction between the metallic core and the graphitic shell can change the local work function of the shell, and further improved the electrocatalytic activities [29-33]. A recent report also suggested the exclusive utility of such hybrid system as an efficient and durable electrocatalyst for OERs [34]. Additionally, the unwanted grain boundaries and defects among the metal sulfide NPs can also be alleviated using this well-designed nanostructure, which can further enhance their electronic conductivity [24, 35]. As such, few-layered graphitic carbon encapsulated transition metal sulfide NPs may be able to deliver a number of physical, chemical and electrical benefits needed for efficient and durable electrocatalysts for OERs.

Herein, for the first time, we report a two-dimensional (2D) carbon nanosheet (CNS) supported few-layered graphitic carbon encapsulated $\mathrm{Ni}_{3} \mathrm{~S}_{2}$ NPs nanocomposite ( $\mathrm{Ni}_{3} \mathrm{~S}_{2} @ \mathrm{C} / \mathrm{CNS}$ ) via facile pyrolysis of the solid reaction precursor of nickel-oleate $\left(\mathrm{Ni}(\mathrm{OA})_{2}\right)$ and $\mathrm{Na}_{2} \mathrm{SO}_{4}$ at $700{ }^{\circ} \mathrm{C}$. The overall formation mechanism for the synthesis of the $\mathrm{Ni}_{3} \mathrm{~S}_{2} @ \mathrm{C} / \mathrm{CNS}$ nanocomposite was systematically investigated based on the emitted gaseous products during the one-step pyrolysis. We found that during the pyrolysis process, the sulfidation of the $\mathrm{Ni}$ precursor by the in situ generated $\mathrm{H}_{2} \mathrm{~S}$ can result in the formation of $\mathrm{Ni}_{3} \mathrm{~S}_{2} \mathrm{NPs}$, which are further encapsulated by a few atomic layers of graphitic carbon through a local chemical vapour deposition (CVD) process. This nanocomposite was applied as an electrocatalyst for OER in 1.0 M KOH electrolyte, showing comparable OER performance and excellent electrocatalytic stability to many transition metal sulfide and precious metal-based electrocatalysts.

\section{Experimental}

\subsection{Chemicals}

Nickel (II) nitrate hexahydrate $\left(\mathrm{Ni}\left(\mathrm{NO}_{3}\right)_{2} \cdot 6 \mathrm{H}_{2} \mathrm{O}\right.$; ACS reagent, $\geq 98 \%$ ), n-Hexane (HPLC grade, $\geq 95 \%$ ), and ruthenium (IV) oxide $\left(\mathrm{RuO}_{2} ; \geq 99.9 \%\right)$ were purchased from Sigma-Aldrich. Sodium oleate 
$\left(\mathrm{C}_{18} \mathrm{H}_{33} \mathrm{O}_{2} \mathrm{Na}\right.$ or $\left.\mathrm{NaOA}\right)$ and sodium sulfate $\left(\mathrm{Na}_{2} \mathrm{SO}_{4}\right.$; AR grade) were bought from TCI Co. and Univar, respectively. Absolute ethanol was of analytical grade and purchased from Chem-Supply. All chemicals were used as received without any further purification.

\subsection{Preparation of $\mathrm{Ni}_{3} \mathrm{~S}_{2} @ \mathrm{C} / \mathrm{CNS}$ nanocomposites}

First, $3.0 \mathrm{mmol}$ of $\mathrm{Ni}\left(\mathrm{NO}_{3}\right)_{2} \cdot 6 \mathrm{H}_{2} \mathrm{O}$ was dissolved in $20 \mathrm{~mL}$ of Milli-Q ${ }^{\circledR}$ water $(18 \mathrm{M} \Omega-\mathrm{cm})$ followed by the addition of $6.0 \mathrm{mmol} \mathrm{NaOA}, 30 \mathrm{~mL}$-hexane and $20 \mathrm{~mL}$ ethanol. This mixture was refluxed at $70{ }^{\circ} \mathrm{C}$ for $1 \mathrm{~h}$ with continuous stirring and cooled down to room temperature. Then, the suspension was transferred into a separatory funnel and the green coloured organic top layer containing $\mathrm{Ni}(\mathrm{OA})_{2}$ was collected in a beaker (Fig. S-1 in the Electronic Supplementary Material (ESM)). Next, 20 $\mathrm{g}$ of $\mathrm{Na}_{2} \mathrm{SO}_{4}$ was added to the green suspension and dried at room temperature for $48 \mathrm{~h}$. This resultant solid mixture was placed in a planetary zirconia ball miller at room temperature at a speed of $500 \mathrm{rpm}$ for $3 \mathrm{~h}$ to prepare a finely ground solid mixture, which was used as a solid reaction precursor for the pyrolysis. After that the greenish coloured solid was pyrolysed from 500 to $900{ }^{\circ} \mathrm{C}$ with a heating ramp of $10{ }^{\circ} \mathrm{C} \mathrm{min}{ }^{-1}$ under continuous Ar flow (20 sccm) and held for $3 \mathrm{~h}$ in a tubular furnace. The samples were allowed to cool down naturally to room temperature under Ar flow. At this stage, the pyrolysed object was washed with copious water and filtered through a $0.45 \mu \mathrm{m}$ nylon membrane. Finally, the nanocomposite, in the form of a black powder, was dried at $60{ }^{\circ} \mathrm{C}$ for $24 \mathrm{~h}$ in air and denoted as $\mathrm{Ni}_{3} \mathrm{~S}_{2} @ \mathrm{C} / \mathrm{CNS}$. A similar method was followed to prepare the CNS sample at $700{ }^{\circ} \mathrm{C}$ without any $\mathrm{Ni}$ precursor. Pure $\mathrm{Ni}_{3} \mathrm{~S}_{2}$ was synthesised according to the literature reported elsewhere [36] and calcined at $700{ }^{\circ} \mathrm{C}$ under $\mathrm{Ar}$ atmosphere. This calcined $\mathrm{Ni}_{3} \mathrm{~S}_{2}$ sample was mixed with the CNS at a weight percentage of $46.2 \%$ (denoted as $\mathrm{Ni}_{3} \mathrm{~S}_{2} / \mathrm{CNS}$ ).

\subsection{Structural characterisations}

The bulk crystal structures of the samples were characterised by powder X-ray diffraction (XRD, Bruker D8 Advance diffractometer, equipped with a graphite monochromator) and Raman spectroscopic (Renishaw 100, $632.8 \mathrm{~nm}$ He-Ne laser) techniques. A scanning electron microscope (SEM, JSM-7001F) and transmission electron microscope (TEM, Philips Tecnai F20) equipped with an Oxford energy-dispersive X-ray spectroscopy (EDS) unit were used to characterise the surface morphology and nanostructural information. The Brunauer-Emmett-Teller (BET) surface area of the prepared material was estimated through nitrogen adsorption-desorption isotherm in Quantachrome Autosorb-1 equipment. The surface chemical composition and the chemical states of the species in the samples were analysed by X-ray photoelectron spectroscopic (XPS, Kratos Axis ULTRA incorporating a $165 \mathrm{~mm}$ hemispherical electron energy analyser) technique. The thermal decomposition processes of the solid reaction precursor were thoroughly analysed by monitoring the real-time emitted gases $\left(\mathrm{H}_{2} \mathrm{O}, \mathrm{CO}, \mathrm{H}_{2} \mathrm{~S}\right.$ and $\left.\mathrm{CO}_{2}\right)$ during the pyrolysis from 100 to $900{ }^{\circ} \mathrm{C}$ with a heating ramp rate of $10{ }^{\circ} \mathrm{C} \mathrm{min}-1$ in an inert (Ar) atmosphere with TG/DSC (TG/DSC, Netzsch STA 449F3) and online mass spectrometer (MS, OmniStar GSD 320).

\subsection{Electrochemical characterisations}

A homogeneous ink was first prepared by dispersing $4.0 \mathrm{mg}$ of catalyst powder in $1 \mathrm{~mL}$ of a solvent mixture of Nafion (5\%), absolute ethanol and Milli- ${ }^{\circledR}$ water with a volume ratio of 1:1:8, followed by continuous ultra-sonication for $1 \mathrm{~h}$. A $12.0 \mu \mathrm{L}$ (loading: $0.24 \mathrm{mg} \mathrm{cm}^{-2}$ ) aliquot of catalyst ink was drop casted on a clean rotating disk electrode (RDE) and dried in air at room temperature. The OER activities of the catalysts were measured in a standard three-electrode system, where the catalyst loaded RDE, an $\mathrm{Hg} / \mathrm{HgO}(1.0 \mathrm{M}$ 
$\mathrm{NaOH}$ ) electrode and platinum mesh acted as the working, reference and counter electrodes, respectively. A potentiostat $(\mathrm{CHI} 760 \mathrm{D}, \mathrm{CH}$ Instruments, USA) was utilised to record the electrochemical responses. The measured current density was normalised to the geometric area of the $\operatorname{RDE}\left(0.196 \mathrm{~cm}^{2}\right)$. The polarisation curves and Tafel plots were measured at scan rates of 5 and $1 \mathrm{mV} \mathrm{s}^{-1}$, respectively. All potentials displayed in this work were converted to the reversible hydrogen electrode (RHE) scale with 95\% $i R$-compensation using the equation $\mathrm{ERHE}_{\mathrm{rHE}}=\mathrm{EHg} / \mathrm{HgO}+0.059 \times \mathrm{pH}+0.098-95 \% i R_{s}$, where $\mathrm{pH}=14$ in $1.0 \mathrm{M} \mathrm{KOH}$ electrolyte and $R_{s}$ stands for the Ohmic resistance of the solution (3-5 $\Omega$ ). Electrochemical impedance spectroscopic (EIS) measurements were conducted under the same experimental configuration at frequencies ranging from $10^{5}$ to $10^{-1} \mathrm{~Hz}$ with the overpotential of $300 \mathrm{mV}$ and applied potential amplitude was $5 \mathrm{mV}$. The electrocatalytic stability was tested using the chronopotentiometry $(\mathrm{CP})$ technique at the current density of $10 \mathrm{~mA} \mathrm{~cm}^{-2}$ for $12 \mathrm{~h}$.

\section{Results and discussion}

\section{Synthesis and structural characteristics}

The one-step solid phase synthesis procedure for the concurrent growth of $\mathrm{Ni}_{3} \mathrm{~S}_{2} @ \mathrm{C} / \mathrm{CNS}$ nanocomposite is schematically illustrated in Fig. 1 (see the experimental section for details). The $\mathrm{Ni}_{3} \mathrm{~S}_{2} @ \mathrm{C} / \mathrm{CNS}$ nanocomposites were prepared by the concurrent sulfidation and carbonisation of the solid reaction precursor of $\mathrm{Ni}(\mathrm{OA})_{2}$ and $\mathrm{Na}_{2} \mathrm{SO}_{4}$ at $700{ }^{\circ} \mathrm{C}$ under Ar atmosphere (Fig. S-1 in the ESM).

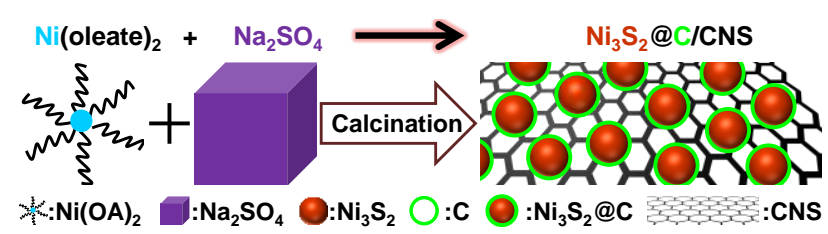

Figure 1 Schematic illustration for the synthesis procedure of $\mathrm{Ni}_{3} \mathrm{~S}_{2} @ \mathrm{C} / \mathrm{CNS}$ nanocomposite.
Fig. 2(a) shows the XRD pattern of the sample prepared at $700{ }^{\circ} \mathrm{C}$ with obvious phase peaks at $2 \theta$ $=21.7,31.1,37.7,44.4,49.8$, and $55.1^{\circ}$ corresponding to the (101), (110), (003), (202), (113) and (122) reflection planes of $\mathrm{Ni}_{3} \mathrm{~S}_{2}$ crystal structure (JCPDS 44-1418), respectively. No obvious diffraction peaks for the CNS were observed; which means that the majority of the carbon nanostructures are in the distorted graphitic form. The distorted graphitic form of CNS can be further evidenced by two distinct Raman peaks at 1349.7 and $1600.6 \mathrm{~cm}^{-1}$ (Fig. 2(b)), corresponding to the D and G-bands, respectively [37-39]. In addition, the weak signals within the range of 200-500 $\mathrm{cm}^{-1}$ are consistent with the Raman spectra reported for $\mathrm{Ni}_{3} \mathrm{~S}_{2}[40,41]$. These XRD and Raman characterisation results confirm that the bulk chemical structure of the $\mathrm{Ni}_{3} \mathrm{~S}_{2} @ \mathrm{C} / \mathrm{CNS}$ nanocomposite is composed of crystalline $\mathrm{Ni}_{3} \mathrm{~S}_{2}$ and distorted graphitic carbon.
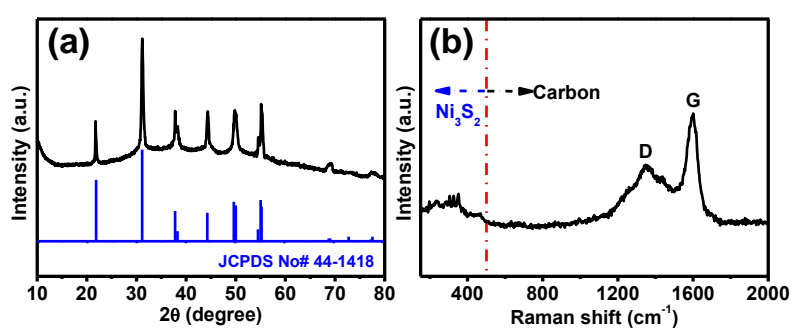

Figure 2 (a) XRD pattern and (b) Raman spectra of the $\mathrm{Ni}_{3} \mathrm{~S}_{2} @ \mathrm{C} / \mathrm{CNS}$ nanocomposite.

The surface morphology and nanostructural properties of the $\mathrm{Ni}_{3} \mathrm{~S}_{2} @ \mathrm{C} / \mathrm{CNS}$ nanocomposite were thoroughly characterised using SEM, TEM and EDS techniques. The SEM images (Figs. 3(a) and 3(b)) show a random arrangement of $\mathrm{Ni}_{3} \mathrm{~S}_{2} \mathrm{NPs}$ and CNS, where the $\mathrm{Ni}_{3} \mathrm{~S}_{2} \mathrm{NPs}$ are dispersed throughout the nanocomposite, as indicated in Fig. $3 \mathrm{~b}$. The composites prepared over $700{ }^{\circ} \mathrm{C}$ were observed to be large chunks (Fig. S-2 in the ESM) and may not be beneficial for OER catalysis. Additionally, the BET surface area of $\mathrm{Ni}_{3} \mathrm{~S}_{2} @ \mathrm{C} / \mathrm{CNS}$ sample was estimated to be $33.34 \mathrm{~m}^{2} \mathrm{~g}^{-1}$ (Fig. S-3 in the ESM). In the TEM image (Fig. 3(c)), the majorities of $\mathrm{Ni}_{3} \mathrm{~S}_{2}$ 
NPs are observed to be within the size of 20-30 nm and are nested on the ultrathin $(\sim 10 \mathrm{~nm}) 2 \mathrm{D}$ CNS matrix (Fig. S-4 in the ESM).
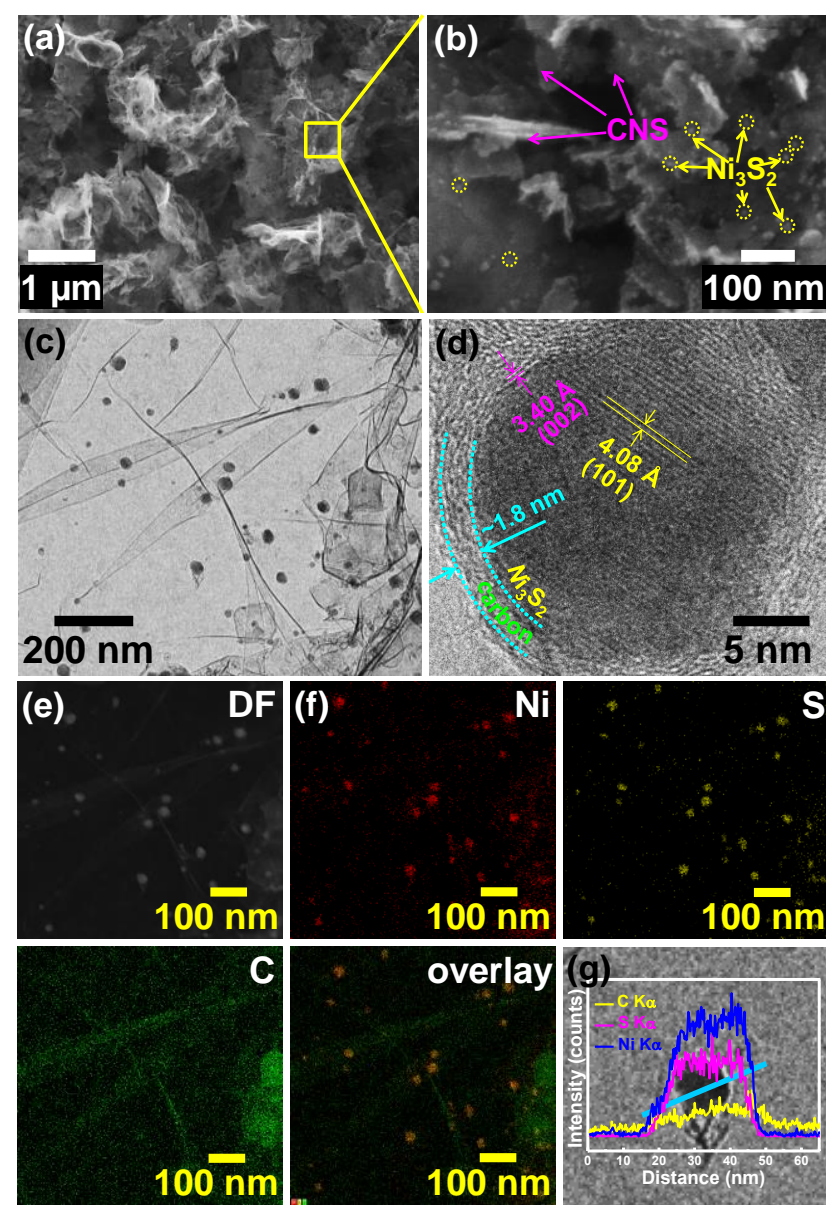

Figure 3 (a, b) SEM images, (c) TEM image, (d) HRTEM image, (e) dark-field TEM, (f) EDS mapping of $\mathrm{Ni}, \mathrm{S}, \mathrm{C}$ elements and their corresponding overlay distribution and $(\mathrm{g})$ the EDS line profile of $\mathrm{Ni}_{3} \mathrm{~S}_{2} @ \mathrm{C}$ nanoparticle. The broken yellow circles and pink arrows in (b) indicate the $\mathrm{Ni}_{3} \mathrm{~S}_{2} @ \mathrm{C} \mathrm{NPs}$ and CNS, respectively. The insert in (g) shows the elemental distribution corresponding to the line drawn over the $\mathrm{Ni}_{3} \mathrm{~S}_{2} @ \mathrm{C}$ nanoparticle.

The high resolution TEM (HRTEM) images clearly show the encapsulation of graphitic carbon layers on $\mathrm{Ni}_{3} \mathrm{~S}_{2} \mathrm{NPs}$ (Fig. 3(d)). The lattice fringes of 3.40 and $4.08 \AA$ can be attributed to the reflection plane of (002) in graphitic carbon and (101) in crystalline $\mathrm{Ni}_{3} \mathrm{~S}_{2}$, respectively. This suggests that $\sim 5$ atomic layers of graphitic carbon with the thickness of $\sim 1.8 \mathrm{~nm}$ have successfully encapsulated the $\mathrm{Ni}_{3} \mathrm{~S}_{2}$ NPs. This thin layer graphitic carbon might provide a geometric confinement to $\mathrm{Ni}_{3} \mathrm{~S}_{2} \mathrm{NPs}$ leading to a close interface contact and can spontaneously prohibit the surface oxidation of $\mathrm{Ni}_{3} \mathrm{~S}_{2}$ with maintaining a promising electrochemical OER activity [42-44].

The EDS measurements were also conducted to visualise the elemental distribution within the entire nanocomposite. As evidenced by Figs. 3(e) and 3(f), the NPs are mainly composed of Ni and S, where the $C$ signals are relatively weak on the NPs, implying the low concentration of $\mathrm{C}$ there. However, the EDS line-profile in Fig. 3(g) clearly shows relatively higher concentration of elemental $\mathrm{C}$ (yellow line) at the edges of the NP, certifying successfully encapsulated $\mathrm{Ni}_{3} \mathrm{~S}_{2} \mathrm{NPs}$ by a few-layered graphitic carbon via this one-step pyrolysis method. Moreover, the EDS pattern (Fig. S-5 in the ESM) obtained from the fields of the $\mathrm{Ni}_{3} \mathrm{~S}_{2} @ \mathrm{C} / \mathrm{CNS}$ nanocomposite indicates an average $\mathrm{Ni} / \mathrm{S}$ atomic composition of 3:2.
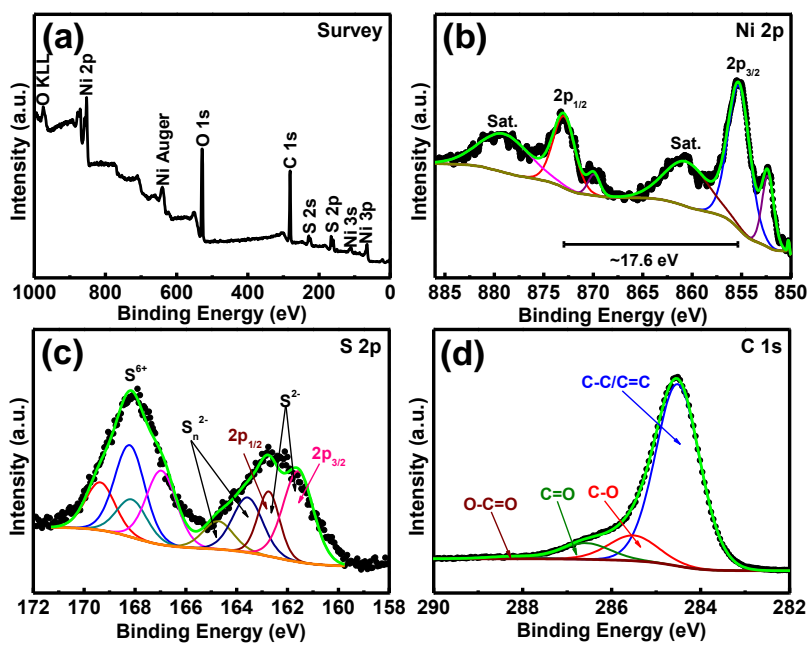

Figure 4 (a) XPS survey spectra, high resolution (b) Ni 2p, (c) S 2p and (d) C 1s spectra of $\mathrm{Ni}_{3} \mathrm{~S}_{2} @ \mathrm{C} / \mathrm{CNS}$ nanocomposite.

The surface chemical states of the as prepared $\mathrm{Ni}_{3} \mathrm{~S}_{2} @ \mathrm{C} / \mathrm{CNS}$ nanocomposite were examined by 
XPS. As shown in Fig. 4(a), Ni, S, O and C elements are dominant in the nanocomposite. The oxidation states of Ni were investigated by the deconvolution of high resolution Ni $2 p$ spectra (Fig. $4(b)$ ). The Ni $2 \mathrm{p}_{3 / 2}$ and $\mathrm{Ni} 2 \mathrm{p}_{1 / 2}$ doublet peaks centred at 855.4 and $873.0 \mathrm{eV}$ accompanied by their respective satellite peaks (denoted as "Sat.") with the split spin-orbit of $\sim 17.6 \mathrm{eV}$ and a characteristic peak at $852.4 \mathrm{eV}$ confirm the formation of $\mathrm{Ni}_{3} \mathrm{~S}_{2}$ crystals, which are consistent with the literature [14, 45, 46]. In Fig. 4(c), two main characteristic peaks for $\mathrm{S}^{2-}$ species at 161.6 and $162.7 \mathrm{eV}$ were observed, which are related to the $S 2 p_{3 / 2}$ and $S 2 p_{1 / 2}$ states [47, 48]. Along with the XPS signals for $\mathrm{S}^{2-}$ states, the $\mathrm{S}^{2-}$ and $\mathrm{S}^{6+}$ states were also observed [38, 48-51]. The C 1s XPS spectrum (Fig. 4(d)) reveals the existence of $\mathrm{C}-\mathrm{C} / \mathrm{C}=\mathrm{C}, \mathrm{C}-\mathrm{O}$, $\mathrm{C}=\mathrm{O}$ and $\mathrm{O}-\mathrm{C}=\mathrm{O}$ bonds in the nanocomposite. Apart from the graphitic bonds, other functional groups of CNS may benefit its binding with $\mathrm{Ni}_{3} \mathrm{~S}_{2} @ \mathrm{C}$ NPs, leading to an improved interfacial connection between the $\mathrm{Ni}_{3} \mathrm{~S}_{2} @ \mathrm{C}$ and $\mathrm{CNS}$, beneficial for electrocatalytic OER applications.

It has been speculated that the amount of $\mathrm{Ni}_{3} \mathrm{~S}_{2}$ in the nanocomposite obtained from the EDS and XPS analysis may be underestimated [31, 52] owing to the few-layered graphitic carbon coatings on $\mathrm{Ni}_{3} \mathrm{~S}_{2}$ NPs. To avoid this discrepancy and to study the thermal stability of the nanocomposite, simultaneous thermogravimetric (TG)/differential scanning calorimetric (DSC) measurements were conducted. The TG/DSC profile (Fig. 5(a)) obtained for the sample burnt from 100 to $900{ }^{\circ} \mathrm{C}$ under air at a heating rate of $10{ }^{\circ} \mathrm{C} \mathrm{min} \mathrm{m}^{-1}$ showed an initial weight loss of $\sim 8.6 \%$ from 100 to $473{ }^{\circ} \mathrm{C}$, implying the evaporation of adsorbed $\mathrm{H}_{2} \mathrm{O}$ and the successive decomposition of labile functional groups (C-O, $\mathrm{C}=\mathrm{O}, \mathrm{O}-\mathrm{C}=\mathrm{O}$, etc.) detected in the XPS measurement. However, a further weight loss of $\sim 48.3 \%$, along with a broad exothermic DSC peak at $\sim 570{ }^{\circ} \mathrm{C}$ was observed, suggesting the simultaneous oxidation of $\mathrm{Ni}_{3} \mathrm{~S}_{2}$ and carbon to their corresponding oxides ( $\mathrm{NiO}$ and $\mathrm{CO}_{2}$ ). Above $650{ }^{\circ} \mathrm{C}$, a stable TG profile reflects the formation of stable $\mathrm{NiO}$, as confirmed by the XRD pattern in Fig. 5(b). Based on the final weight of $\mathrm{NiO}$ remaining as residue, the original fraction of $\mathrm{Ni}_{3} \mathrm{~S}_{2}$ in the nanocomposite was calculated to be $46.2 \%$ by weight.
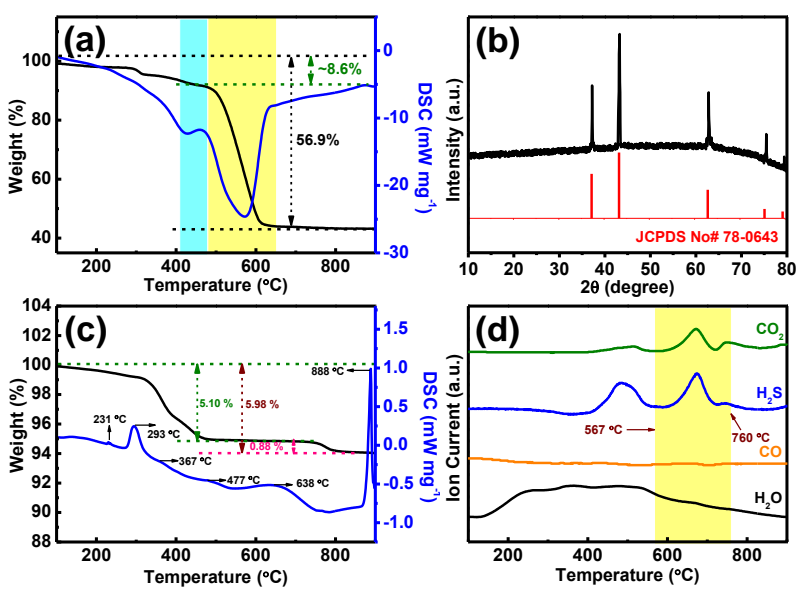

Figure 5 (a) TG/DSC curves obtained for $\mathrm{Ni}_{3} \mathrm{~S}_{2} @ \mathrm{C} / \mathrm{CNS}$ sample in air from 100 to $900{ }^{\circ} \mathrm{C}$; (b) XRD pattern of the materials remaining after burning the $\mathrm{Ni}_{3} \mathrm{~S}_{2} @ \mathrm{C} / \mathrm{CNS}$ nanocomposite at $900{ }^{\circ} \mathrm{C}$ in air; (c) TG/DSC and (d) MS curves obtained from the pyrolysis of the solid precursor $\left(\mathrm{Ni}(\mathrm{OA})_{2}+\mathrm{Na}_{2} \mathrm{SO}_{4}\right)$ under $\mathrm{Ar}$ protection from 100 to $900{ }^{\circ} \mathrm{C}$ with a heating ramp of $10{ }^{\circ} \mathrm{C} \mathrm{min}^{-1}$.

The instantaneous TG/DSC-MS measurements were performed to understand the formation mechanism of $\mathrm{Ni}_{3} \mathrm{~S}_{2} @ \mathrm{C} / \mathrm{CNS}$ nanocomposite. According to our previous work [50, 53], the concurrently grown products are heavily dependent on the decomposition characteristics of each existing component in the solid reaction precursor. Also, a certain quantity of thermal energy is essential to trigger each decomposition event and the relevant chemical reactions inside the pyrolysis tube. A synchronous TG/DSC-MS measurement enables us to monitor the TG/DSC profile along with the emitted gaseous products during pyrolysis. The TG/DSC-MS measurement of the solid reaction precursor was performed under the same experimental conditions used for the nanocomposite fabrication. As shown in Fig. 5(c), 
the initial major breakthrough started at $293{ }^{\circ} \mathrm{C}$ and continued up to $500{ }^{\circ} \mathrm{C}$ with a weight loss of $~ 5.10 \%$, as evidenced by the strong endothermic DSC peak and simultaneous peaked emissions (Fig. 5(d)) of the gaseous products $\left(\mathrm{H}_{2} \mathrm{O}, \mathrm{H}_{2} \mathrm{~S}, \mathrm{CO}_{2}\right)$. It suggests that the decomposition of $\mathrm{Ni}(\mathrm{OA})_{2}$ resulted in the formation of $\mathrm{Ni}^{0} \mathrm{NPs}$ (Figs. S-2 and S-6 in the ESM) and amorphous carbon (Eq. 1). A broad endothermic peak and an obvious weight loss of $0.88 \%$ (Fig. 5(c)) from 567 to $760{ }^{\circ} \mathrm{C}$ (Fig. 5(d)) may arise from the reduction of $\mathrm{Na}_{2} \mathrm{SO}_{4}$ (Eq. 2) by carbon to produce $\mathrm{Na}_{2} \mathrm{~S}$. Thereafter, the hydrolysis of $\mathrm{Na}_{2} \mathrm{~S}$ (Eq. 3) leads to the formation of $\mathrm{H}_{2} \mathrm{~S}$, as supported by the MS peaked $\mathrm{H}_{2} \mathrm{~S}$ emission (Fig. 5(d)). After that, $\mathrm{H}_{2} \mathrm{~S}$ can further sulfidise the $\mathrm{Ni}^{0} \mathrm{NPs}$ to yield $\mathrm{Ni}_{3} \mathrm{~S}_{2} \mathrm{NPs}$ (Eq. 4). Furthermore, the $\mathrm{Na}_{2} \mathrm{SO}_{4}$ salt not only assisted nanostructure formation on its surface but also provided the desired amount of sulfur sources for the sulfidation of metallic Ni NPs. Based on the aforementioned discussion and corresponding XRD analysis (Fig. S-6 in the ESM), a plausible reaction mechanism is outlined below.

$\mathrm{Ni}(\mathrm{OA})_{2} \stackrel{\Delta}{\rightarrow} \mathrm{Ni}^{0}+\mathrm{C}_{x} \mathrm{H}_{y} \mathrm{O}_{z}+\mathrm{CO}_{2}$

$\mathrm{C}_{\mathrm{x}} \mathrm{H}_{y} \mathrm{O}_{z}+\mathrm{Na}_{2} \mathrm{SO}_{4} \stackrel{\Delta}{\rightarrow} \mathrm{Na}_{2} \mathrm{~S}+\mathrm{CO}_{2}+\mathrm{H}_{2} \mathrm{O}$

$\mathrm{Na}_{2} \mathrm{~S}+\mathrm{H}_{2} \mathrm{O} \stackrel{\Delta}{\rightarrow} \mathrm{H}_{2} \mathrm{~S}+\mathrm{NaOH}$

$\mathrm{Ni} i^{0}+\mathrm{C}_{x} \mathrm{H}_{y} \mathrm{O}_{z}+\mathrm{H}_{2} \mathrm{~S} \stackrel{\Delta}{\rightarrow} \mathrm{Ni}_{3} \mathrm{~S}_{2} @ \mathrm{C} / \mathrm{CNS}+\mathrm{H}_{2} \mathrm{O}$

It is noteworthy that the nanostructure obtained in this work is very different from that achieved in our previous work [50] owing to the different pyrolysis mechanism. As shown in Fig. 3d, the carbon used to encapsulate $\mathrm{Ni}_{3} \mathrm{~S}_{2} \mathrm{NPs}$ was in the graphitic form, whereas the carbon in the CNS was distorted or partly amorphous. This discriminative nature of carbonisation at this moderately high temperature pyrolysis event may arise from the catalytic graphitisation characteristics of metallic $\mathrm{Ni}^{0}$ NPs [54, 55] formed at lower pyrolysis temperatures $\left(<700{ }^{\circ} \mathrm{C}\right)$ (Fig. S-6 in the ESM). The high carbon diffusion coefficient $\left(2 \times 10^{-11} \mathrm{~m}^{2} \mathrm{~s}^{-1}\right)$ in metallic Ni [56, 57] can result a local CVD [58] growth of graphitic carbon on $\mathrm{Ni}_{3} \mathrm{~S}_{2} \mathrm{NPs}$. During the simultaneous sulfidation and carbonisation process which took place at $700{ }^{\circ} \mathrm{C}$, carbon atoms are believed to diffuse into the $\mathrm{Ni}^{0} \mathrm{NPs}$ and are partially displaced by the sulfur atoms sourcing from the in situ generated $\mathrm{H}_{2} \mathrm{~S}$ gas to form $\mathrm{Ni}_{3} \mathrm{~S}_{2}$ NPs. Through this displacement, carbon atoms may get precipitated on $\mathrm{Ni}_{3} \mathrm{~S}_{2}$ NPs surface which in turn led to the formation of few-layered graphitic carbon encapsulating layer and thereby the final $\mathrm{Ni}_{3} \mathrm{~S}_{2} @ \mathrm{C} / \mathrm{CNS}$ nanocomposite.

\section{Electrocatalytic performances}

The electrocatalytic OER performances of the electrocatalysts were examined in $1.0 \mathrm{M} \mathrm{KOH}$ electrolyte using a standard three-electrode system (see the experimental section for details). To identify the function of few-layered graphitic carbon on $\mathrm{Ni}_{3} \mathrm{~S}_{2} \mathrm{NPs}$, two control samples including $\mathrm{Ni}_{3} \mathrm{~S}_{2} / \mathrm{CNS}, \mathrm{Ni}_{3} \mathrm{~S}_{2}$ (Fig. S-7 in the ESM) were also tested under identical conditions on a glassy carbon electrode (GCE).

As it evident from the polarisation curves (Fig. 6(a)), the CNS is not active to the catalytic OERs. Also, the products obtained below or over $700{ }^{\circ} \mathrm{C}$ showed poor electrocatalytic performances, which can be ascribed to the severely destroyed nanostructures and various crystal phases (Figs. S-2, S-6 and S-8 in the ESM). Interestingly, the product synthesised at $700{ }^{\circ} \mathrm{C}\left(\mathrm{Ni}_{3} \mathrm{~S}_{2} @ \mathrm{C} / \mathrm{CNS}\right)$ exhibits the earliest onset potential of $\approx 1.45 \mathrm{~V}$ (vs. RHE), which is fairly close to that of the benchmark $\mathrm{RuO}_{2}$ and slightly better than those of $\mathrm{Ni}_{3} \mathrm{~S}_{2} / \mathrm{CNS}$ and $\mathrm{Ni}_{3} \mathrm{~S}_{2}$ catalysts. However, the overpotential required to reach the current density of $10 \mathrm{~mA} \mathrm{~cm}^{-2}$ is $298 \mathrm{mV}$ for the $\mathrm{Ni}_{3} \mathrm{~S}_{2} @ \mathrm{C} / \mathrm{CNS}$ electrode, which is 10, 26 and $37 \mathrm{mV}$ lower than those of $\mathrm{RuO}_{2}, \mathrm{Ni}_{3} \mathrm{~S}_{2} / \mathrm{CNS}$ and $\mathrm{Ni}_{3} \mathrm{~S}_{2}$, respectively. The smallest overpotential of $\mathrm{Ni}_{3} \mathrm{~S}_{2} @ \mathrm{C} / \mathrm{CNS}$ among all considered catalysts 
reveals that the encapsulation of few-layered graphitic carbon can improve the OER performance. It is also worthwhile to mention that $\mathrm{Ni}_{3} \mathrm{~S}_{2}$ and $\mathrm{Ni}_{3} \mathrm{~S}_{2} / \mathrm{CNS}$ samples showed a peak at $\sim 1.43 \mathrm{~V}$ (see Fig. 6(a)), which can be attributed to the reversible redox reaction of $\mathrm{Ni}(\mathrm{II}) \leftrightarrow \mathrm{Ni}(\mathrm{III})$ in alkaline solution $[59,60]$. Whereas, a tiny fraction of peak current was observed for $\mathrm{Ni}_{3} \mathrm{~S}_{2} @ \mathrm{C} / \mathrm{CNS}$ sample, meaning the successful protection of $\mathrm{Ni}_{3} \mathrm{~S}_{2} \mathrm{NPs}$ due to the few-layered graphitic carbon encapsulation.
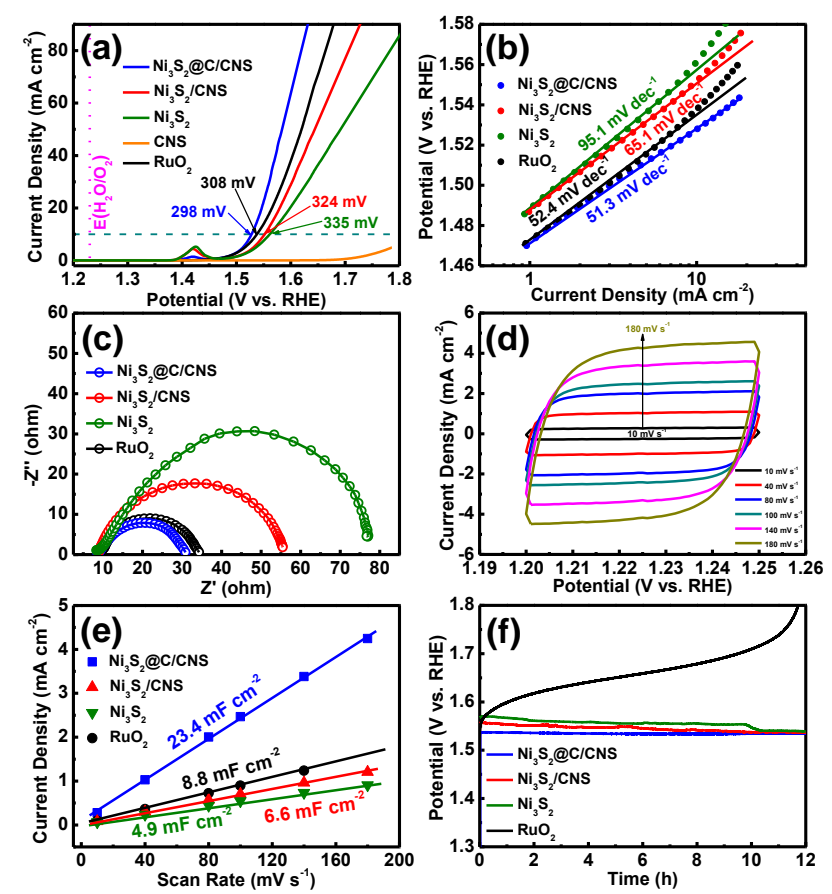

Figure 6 (a) Polarisation curves, (b) Tafel plots, (c) Nyquist plots of $\mathrm{Ni}_{3} \mathrm{~S}_{2} @ \mathrm{C} / \mathrm{CNS}, \mathrm{Ni}_{3} \mathrm{~S}_{2} / \mathrm{CNS}, \mathrm{Ni}_{3} \mathrm{~S}_{2}$ and $\mathrm{RuO}_{2}$; (d) cyclic voltammograms of the $\mathrm{Ni}_{3} \mathrm{~S}_{2} @ \mathrm{C} / \mathrm{CNS}$ catalyst at scan rates of 10 to $180 \mathrm{mV} \mathrm{s}^{-1}$; (e) plots of current densities at $1.225 \mathrm{~V}$ vs. scan rates of $\mathrm{Ni}_{3} \mathrm{~S}_{2} @ \mathrm{C} / \mathrm{CNS}, \mathrm{Ni}_{3} \mathrm{~S}_{2} / \mathrm{CNS}, \mathrm{Ni}_{3} \mathrm{~S}_{2}$ and $\mathrm{RuO}_{2}$; (f) chronopotentiometric (CP) plots of the $\mathrm{Ni}_{3} \mathrm{~S}_{2} @ \mathrm{C} / \mathrm{CNS}$, $\mathrm{Ni}_{3} \mathrm{~S}_{2} / \mathrm{CNS}, \mathrm{Ni}_{3} \mathrm{~S}_{2}$ and $\mathrm{RuO}_{2}$ catalyst in $1.0 \mathrm{M} \mathrm{KOH}$ electrolyte.

To gain insight into the OER kinetics, Tafel plots were constructed as shown in Fig. 6(b). The Ni332@C/CNS electrode shows a Tafel slope of 51.3 $\mathrm{mV} \operatorname{dec}^{-1}$, which is slightly smaller than that of $\mathrm{RuO}_{2}$ (52.4 mV dec $\left.{ }^{-1}\right)$, however, significantly smaller than $\mathrm{Ni}_{3} \mathrm{~S}_{2} / \mathrm{CNS}\left(65.1 \mathrm{mV} \mathrm{dec}{ }^{-1}\right)$ and $\mathrm{Ni}_{3} \mathrm{~S}_{2}(95.1 \mathrm{mV}$ $\left.\mathrm{dec}^{-1}\right)$. The relatively smaller Tafel slope suggests that the superior OER kinetics of the $\mathrm{Ni}_{3} \mathrm{~S}_{2} @ \mathrm{C} / \mathrm{CNS}$ catalysts.

Typically, the OER kinetics is associated with the charge transfer process, which was further investigated by electrochemical impedance spectroscopy (EIS). As displayed in Fig. 6(c), the charge transfer resistance $\left(R_{c t}\right)$ of $\mathrm{Ni}_{3} \mathrm{~S}_{2} / \mathrm{CNS}(46.6 \Omega)$ is $32.4 \%$ lower than that of $\mathrm{Ni}_{3} \mathrm{~S}_{2}(68.9 \Omega)$ due to the introduction of conductive CNS. After few-layered graphitic carbon encapsulation on $\mathrm{Ni}_{3} \mathrm{~S}_{2} \mathrm{NPs}$, a further improvement $(52.8 \%)$ on the $R_{c t}$ value is observed for $\mathrm{Ni}_{3} \mathrm{~S}_{2} @ \mathrm{C} / \mathrm{CNS}(22.0 \Omega$ ) catalyst. Also, the $R_{c t}$ value of $\mathrm{Ni}_{3} \mathrm{~S}_{2} @ \mathrm{C} / \mathrm{CNS}$ is even lower than that of the benchmark $\mathrm{RuO}_{2}$ catalyst $(25.5 \Omega)$. The small charge transfer resistance is consistent with the conclusion through the comparison of Tafel slope values, which can be ascribed to the tight binding between the $\mathrm{Ni}_{3} \mathrm{~S}_{2} \mathrm{NPs}$ and graphitic carbon layers, as demonstrated by the HRTEM (see Fig. 3(d)). Obviously, the introduction of carbon encapsulating layer on $\mathrm{Ni}_{3} \mathrm{~S}_{2} \mathrm{NPs}$ induces an enhanced catalytic activities, which is consistent with the literature $[30,61]$ but the identification of the real active sites in this hybrid core-shell heterostructure still remains unclear.

In addition to the kinetic study, the electrochemical active surface area of the catalyst was examined by comparing the electrochemical double-layer capacitance $\left(C_{d l}\right)$ under non-Faradaic potential window [62]. The corresponding $C_{d l}$ values of all the electrocatalysts were calculated from the cyclic voltammograms (Figs. 6(d) and S-9 in the ESM) and presented in Fig. 6(e). The highest Cdl value of $\mathrm{Ni}_{3} \mathrm{~S}_{2} @ \mathrm{C} / \mathrm{CNS}\left(23.4 \mathrm{mF} \mathrm{cm}^{-2}\right)$ with

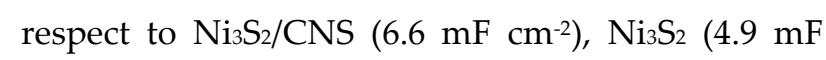
$\left.\mathrm{cm}^{-2}\right)$ and $\mathrm{RuO}_{2}\left(8.8 \mathrm{mF} \mathrm{cm}{ }^{-2}\right)$ indicates the largest amount of electrocatalytic active sites. This is because of the aggregation of $\mathrm{Ni}_{3} \mathrm{~S}_{2} \mathrm{NPs}$ can be prohibited by the graphitic carbon layers on NPs during the synthesis, which can, therefore, increase the surface area of the catalyst. 
Based on the aforementioned electrochemical measurements, $\mathrm{Ni}_{3} \mathrm{~S}_{2} @ \mathrm{C} / \mathrm{CNS}$ shows improved OER activities due to the encapsulation of few graphitic carbon layers. It is worth noting that the performance of this novel $\mathrm{Ni}_{3} \mathrm{~S}_{2} @ \mathrm{C} / \mathrm{CNS}$ electrocatalysts is also better than that of many other nickel sulfide catalysts reported to date for OERs (see Table S-1 in the ESM).

Besides the thermodynamic and kinetics assessments, the electrocatalytic OER stability was also tested by chronopotentiometric (CP) measurement at the current density of $10 \mathrm{~mA} \mathrm{~cm}^{-2}$. As displayed in Fig. 6(f), Ni3 $S_{2} @$ C/CNS showed impressive electrocatalytic durability in $1.0 \mathrm{M} \mathrm{KOH}$ electrolyte where the operating potential remained close to $\approx 1.537 \mathrm{~V}$ (vs. RHE) for $12 \mathrm{~h}$ of testing period. On the other hand, $\mathrm{Ni}_{3} \mathrm{~S}_{2} / \mathrm{CNS}$ and $\mathrm{Ni}_{3} \mathrm{~S}_{2}$ electrodes were found to be gradually activated with an obvious trip to a decreased overpotential after $10 \mathrm{~h}$ of OER test, which is possibly related to the electrochemical conversion of $\mathrm{Ni}_{3} \mathrm{~S}_{2}$ to its corresponding oxyhydroxide or vice versa $[8,18,19$, 63]. In contrast, the electrocatalytic performance of $\mathrm{RuO}_{2}$ was recorded to get decreased rapidly with time. Therefore, the steady state catalytic behaviour of $\mathrm{Ni}_{3} \mathrm{~S}_{2} @ \mathrm{C} / \mathrm{CNS}$ catalyst in the CP test indicates the spontaneous protection of $\mathrm{Ni}_{3} \mathrm{~S}_{2} \mathrm{NPs}$ due to the few-layered graphitic carbon encapsulation.
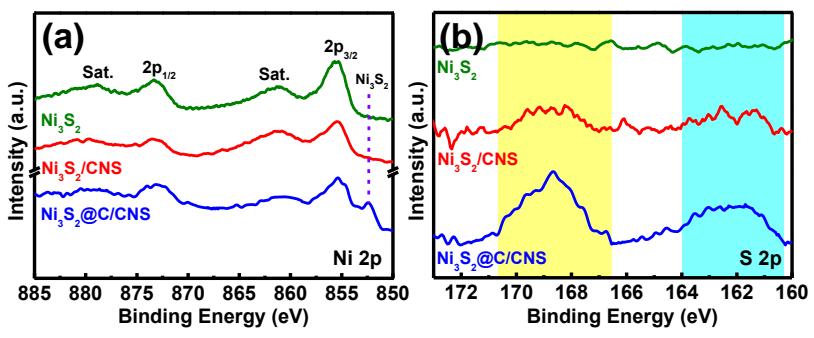

Figure 7 XPS spectra of (a) $\mathrm{Ni} 2 \mathrm{p}$ and (b) $\mathrm{S} 2 \mathrm{p}$ of $\mathrm{Ni}_{3} \mathrm{~S}_{2} @ \mathrm{C} / \mathrm{CNS}, \mathrm{Ni}_{3} \mathrm{~S}_{2} / \mathrm{CNS}$ and $\mathrm{Ni}_{3} \mathrm{~S}_{2}$ after $12 \mathrm{~h}$ of OER test in $1.0 \mathrm{M} \mathrm{KOH}$.

To identify the role of carbon encapsulation in enhancing the electrocatalytic OER stability, XPS measurements were conducted on the sample used for the $12 \mathrm{~h}$ OER durability test. As evidenced by Fig. 7(a), the characteristic peak of $\mathrm{Ni}_{3} \mathrm{~S}_{2}(852.4 \mathrm{eV})$ is retained for $\mathrm{Ni}_{3} \mathrm{~S}_{2} @ \mathrm{C} / \mathrm{CNS}$, whereas this XPS signals are disappeared for both $\mathrm{Ni}_{3} \mathrm{~S}_{2} / \mathrm{CNS}$ and $\mathrm{Ni}_{3} \mathrm{~S}_{2}$ samples. This scenario indicates the unavoidable electrochemical oxidation of $\mathrm{Ni}_{3} \mathrm{~S}_{2}$ to oxyhydroxide or hydrated oxide in the absence of carbon encapsulation [14, 46].

Similar phenomenon was also observed from the S $2 p$ XPS spectra as presented in Fig. 7(b). The sulfur species are found to be depleted for $\mathrm{Ni}_{3} \mathrm{~S}_{2} / \mathrm{CNS}$ and $\mathrm{Ni}_{3} \mathrm{~S}_{2}$ samples. However, the $\mathrm{S} 2 \mathrm{p}$ spectrum for $\mathrm{Ni}_{3} \mathrm{~S}_{2} @ \mathrm{C} / \mathrm{CNS}$ sample displayed almost unchanged XPS signal after the $12 \mathrm{~h}$ OER durability test, which suggests a negligible change in the sulfur chemical states. Therefore, it confirms that the encapsulation of few-layered graphitic carbon on $\mathrm{Ni}_{3} \mathrm{~S}_{2}$ NPs has successfully secured the parent chemical structure and ensured an excellent electrocatalytic OER stability, as suggested by the CP measurements (Fig. 6(f)).

\section{Conclusions}

In summary, the few-layered graphitic carbon encapsulated heazlewoodite nanoparticle catalyst supported on the 2D carbon nanosheet $\left(\mathrm{Ni}_{3} \mathrm{~S}_{2} @ \mathrm{C} / \mathrm{CNS}\right)$ was successfully fabricated using a facile, cheap and one-step solid phase pyrolysis approach. The formation mechanism of $\mathrm{Ni}_{3} \mathrm{~S}_{2} @ \mathrm{C} / \mathrm{CNS}$ was comprehensively studied using a combined TG/DSC-MS and XRD analysis, which demonstrates a sequence of chemical reactions occurring during the pyrolysis process along with a local CVD growth of graphitic carbon layer. The electrocatalytic performances reveal the two-fold functions of carbon encapsulation. First, the smaller Tafel slope and charge transfer resistance compared to those of benchmark $\mathrm{RuO}_{2}$ and control samples suggest that the few-layered graphitic carbon can significantly improve electronic conductivity. Second, the remarkable electrocatalytic durability is achieved by avoiding the electrochemical oxidation of $\mathrm{Ni}_{3} \mathrm{~S}_{2}$ due to the protection of the graphitic carbon layers. 
We, therefore, believe that the encapsulation of metal-sulfide NPs by the few-layered conductive and chemically inert graphitic carbon is a feasible and effective way of enhancing the activity and durability of electrocatalysts for OER, which can also be useful to the molecular design of novel nanomaterials involved in energy conversion and storage applications.

\section{Acknowledgements}

This work was financially supported by Australian Research Council (ARC) Discovery Project and the National Natural Science Foundation of China (Grant No. 51372248, 51432009).

Electronic Supplementary Material: Supplementary material (SEM, EDS, XRD and Electrochemical characterisations) is available in the online version of this article at http://dx.doi.org/10.1007/s12274-*******_* (automatically inserted by the publisher).

\section{References}

[1] Luo, J.; Im, J. H.; Mayer, M. T.; Schreier, M.; Nazeeruddin, M. K.; Park, N. G.; Tilley, S. D.; Fan, H. J.; Grätzel, M. Water photolysis at $12.3 \%$ efficiency via perovskite photovoltaics and earth-abundant catalysts. Science 2014, 345, 1593-1596.

[2] Subbaraman, R.; Tripkovic, D.; Chang, K. C.; Strmcnik, D.; Paulikas, A. P.; Hirunsit, P.; Chan, M.; Greeley, J.; Stamenkovic, V.; Markovic, N. M. Trends in activity for the water electrolyser reactions on $3 \mathrm{~d} \mathrm{M}(\mathrm{Ni}, \mathrm{Co}, \mathrm{Fe}, \mathrm{Mn})$ hydr(oxy)oxide catalysts. Nat. Mater. 2012, 11, 550-557.

[3] Freunberger, S. A. Batteries: charging ahead rationally. Nat. Energy 2016, 1, 16074.

[4] Dau, H.; Limberg, C.; Reier, T.; Risch, M.; Roggan, S.; Strasser, P. The mechanism of water oxidation: from electrolysis via homogeneous to biological catalysis. ChemCatChem 2010, 2, 724-761.

[5] Matsumoto, Y.; Sato, E. Electrocatalytic properties of transition metal oxides for oxygen evolution reaction. Mater. Chem. Phys. 1986, 14, 397-426.

[6] Gong, M.; Dai, H. A mini review of NiFe-based materials as highly active oxygen evolution reaction electrocatalysts. Nano Res. 2015, 8, 23-39.

[7] Wang, L.; Geng, J.; Wang, W.; Yuan, C.; Kuai, L.; Geng, B. Facile synthesis of $\mathrm{Fe} / \mathrm{Ni}$ bimetallic oxide solid-solution nanoparticles with superior electrocatalytic activity for oxygen evolution reaction. Nano Res. 2015, 8 , 3815-3822.

[8] Li, H.; Shao, Y.; Su, Y.; Gao, Y.; Wang, X. Vapor-phase atomic layer deposition of nickel sulfide and its application for efficient oxygen-evolution electrocatalysis. Chem. Mater. 2016, 28, 1155-1164.

[9] Yang, J.; Zhu, G.; Liu, Y.; Xia, J.; Ji, Z.; Shen, X.; Wu, S. $\mathrm{Fe}_{3} \mathrm{O}_{4}$-decorated $\mathrm{Co}_{9} \mathrm{~S}_{8}$ nanoparticles in situ grown on reduced graphene oxide: a new and efficient electrocatalyst for oxygen evolution reaction. Adv. Funct. Mat. 2016, 26, 4712-4721.

[10] Dou, S.; Tao, L.; Huo, J.; Wang, S.; Dai, L. Etched and doped $\mathrm{Co}_{9} \mathrm{~S}_{8} /$ graphene hybrid for oxygen electrocatalysis. Energy Environ. Sci. 2016, 9, 1320-1326.

[11] Falkowski, J. M.; Concannon, N. M.; Yan, B.; Surendranath, Y. Heazlewoodite, $\mathrm{Ni}_{3} \mathrm{~S}_{2}$ : a potent catalyst for oxygen reduction to water under benign conditions. $J$. Am. Chem. Soc. 2015, 137, 7978-7981.

[12] Li, J.; Shen, P. K.; Tian, Z. One-step synthesis of $\mathrm{Ni}_{3} \mathrm{~S}_{2}$ nanowires at low temperature as efficient electrocatalyst for hydrogen evolution reaction. Int. J. Hydrog. Energy, in press, DOI: 10.1016/j.ijhydene.2016.1003.1068.

[13] Gong, M.; Wang, D. Y.; Chen, C. C.; Hwang, B. J.; Dai, H. A mini review on nickel-based electrocatalysts for alkaline hydrogen evolution reaction. Nano Res. 2016, 9 , 28-46.

[14] Zhou, W.; Wu, X. J.; Cao, X.; Huang, X.; Tan, C.; Tian, J.; Liu, H.; Wang, J.; Zhang, H. $\mathrm{Ni}_{3} \mathrm{~S}_{2}$ nanorods/Ni foam composite electrode with low overpotential for electrocatalytic oxygen evolution. Energy Environ. Sci. 2013, 6, 2921-2924.

[15] Shang, X.; Li, X.; Hu, W. H.; Dong, B.; Liu, Y. R.; Han, G. Q.; Chai, Y. M.; Liu, Y. Q.; Liu, C. G. In situ growth of $\mathrm{Ni}_{\mathrm{x}} \mathrm{S}_{\mathrm{y}}$ controlled by surface treatment of nickel foam as efficient electrocatalyst for oxygen evolution reaction. Appl. Surf. Sci. 2016, 378, 15-21.

[16] Wu, Y.; Li, G. D.; Liu, Y.; Yang, L.; Lian, X.; Asefa, T.; 
Zou, X. Overall water splitting catalyzed efficiently by an ultrathin nanosheet-built, hollow $\mathrm{Ni}_{3} \mathrm{~S}_{2}$-based electrocatalyst. Adv. Funct. Mat. 2016, 26, 4839-4847.

[17] Feng, L. L.; Yu, G.; Wu, Y.; Li, G. D.; Li, H.; Sun, Y.; Asefa, T.; Chen, W.; Zou, X. High-index faceted $\mathrm{Ni}_{3} \mathrm{~S}_{2}$ nanosheet arrays as highly active and ultrastable electrocatalysts for water splitting. J. Am. Chem. Soc. 2015, 137, 14023-14026.

[18] Chen, W.; Wang, H.; Li, Y.; Liu, Y.; Sun, J.; Lee, S.; Lee, J. S.; Cui, Y. In situ electrochemical oxidation tuning of transition metal disulfides to oxides for enhanced water oxidation. ACS Cent. Sci. 2015, 1, 244-251.

[19] Mabayoje, O.; Shoola, A.; Wygant, B. R.; Mullins, C. B. The role of anions in metal chalcogenide oxygen evolution catalysis: electrodeposited thin films of nickel sulfide as "pre-catalysts". ACS Energy Lett. 2016, 1, 195-201.

[20] Liu, T.; Liang, Y.; Liu, Q.; Sun, X.; He, Y.; Asiri, A. M. Electrodeposition of cobalt-sulfide nanosheets film as an efficient electrocatalyst for oxygen evolution reaction. Electrochem. Commun. 2015, 60, 92-96.

[21] Liu, X.; You, B.; Yu, X. Y.; Chipman, J.; Sun, Y. Electrochemical oxidation to construct a nickel sulfide/oxide heterostructure with improvement of capacitance. J. Mater. Chem. A 2016, 4, 11611-11615.

[22] Lou, X. W.; Li, C. M.; Archer, L. A. Designed synthesis of coaxial $\mathrm{SnO}_{2} @$ carbon hollow nanospheres for highly reversible lithium storage. Adv. Mater. 2009, 21, 2536-2539.

[23] Zhu, C.; Xu, F.; Chen, J.; Min, H.; Dong, H.; Tong, L.; Qasim, K.; Li, S.; Sun, L. Nitrogen-doped carbon onions encapsulating metal alloys as efficient and stable catalysts for dye-sensitized solar cells. J. Power Sources 2016, 303 , 159-167.

[24] Bi, E.; Chen, H.; Yang, X.; Peng, W.; Gratzel, M.; Han, L. A quasi core-shell nitrogen-doped graphene/cobalt sulfide conductive catalyst for highly efficient dye-sensitized solar cells. Energy Environ. Sci. 2014, 7, 2637-2641.

[25] Feng, L. L.; Li, G. D.; Liu, Y.; Wu, Y.; Chen, H.; Wang, Y.; Zou, Y. C.; Wang, D.; Zou, X. Carbon-armored $\mathrm{Co}_{9} \mathrm{~S}_{8}$ nanoparticles as all-pH efficient and durable $\mathrm{H}_{2}$-evolving electrocatalysts. ACS Appl. Mater. Interfaces 2015, 7,
980-988.

[26] Zhou, Y.; Jin, P.; Zhou, Y. Synthesis of carbon-encapsulated cobalt sulfide nanoparticles and their electrochemical property. Ionics 2016, 22, 2239-2243.

[27] Lou, P.; Tan, Y.; Lu, P.; Cui, Z.; Guo, X. Novel one-step gas-phase reaction synthesis of transition metal sulfide nanoparticles embedded in carbon matrices for reversible lithium storage. J. Mater. Chem. A 2016, 4, 16849-16855.

[28] Simon, P.; Gogotsi, Y. Materials for electrochemical capacitors. Nat. Mater. 2008, 7, 845-854.

[29] Deng, J.; Ren, P.; Deng, D.; Bao, X. Enhanced electron penetration through an ultrathin graphene layer for highly efficient catalysis of the hydrogen evolution reaction. Angew. Chem. Int. Ed. 2015, 54, 2100-2104.

[30] Deng, D.; Yu, L.; Chen, X.; Wang, G.; Jin, L.; Pan, X.; Deng, J.; Sun, G.; Bao, X. Iron encapsulated within pod-like carbon nanotubes for oxygen reduction reaction. Angew. Chem. Int. Ed. 2013, 52, 371-375.

[31] Tavakkoli, M.; Kallio, T.; Reynaud, O.; Nasibulin, A. G.; Johans, C.; Sainio, J.; Jiang, H.; Kauppinen, E. I.; Laasonen, K. Single-shell carbon-encapsulated iron nanoparticles: synthesis and high electrocatalytic activity for hydrogen evolution reaction. Angew. Chem. Int. Ed. 2015, 54, 4535-4538.

[32] Taubert, S.; Laasonen, K. The molecular and magnetic structure of carbon-enclosed and partially covered $\mathrm{Fe}_{55}$ particles. Phys. Chem. Chem. Phys. 2014, 16, 3648-3660.

[33] Liu, Y.; Jiang, H.; Zhu, Y.; Yang, X.; Li, C. Transition metals $(\mathrm{Fe}, \mathrm{Co}$, and $\mathrm{Ni}$ ) encapsulated in nitrogen-doped carbon nanotubes as bi-functional catalysts for oxygen electrode reactions. J. Mater. Chem. A 2016, 4, 1694-1701.

[34] Cui, X.; Ren, P.; Deng, D.; Deng, J.; Bao, X. Single layer graphene encapsulating non-precious metals as high-performance electrocatalysts for water oxidation. Energy Environ. Sci. 2016, 9, 123-129.

[35] Burschka, J.; Brault, V.; Ahmad, S.; Breau, L.; Nazeeruddin, M. K.; Marsan, B.; Zakeeruddin, S. M.; Gratzel, M. Influence of the counter electrode on the photovoltaic performance of dye-sensitized solar cells using a disulfide/thiolate redox electrolyte. Energy Environ. Sci. 2012, 5, 6089-6097. 
[36] Lin, H.; Liu, F.; Wang, X.; Ai, Y.; Yao, Z.; Chu, L.; Han, S.; Zhuang, X. Graphene-coupled flower-like $\mathrm{Ni}_{3} \mathrm{~S}_{2}$ for a free-standing 3D aerogel with an ultra-high electrochemical capacity. Electrochim. Acta 2016, 191, 705-715.

[37] Jang, B.; Park, M.; Chae, O. B.; Park, S.; Kim, Y.; Oh, S. M.; Piao, Y.; Hyeon, T. Direct synthesis of self-assembled ferrite/carbon hybrid nanosheets for high performance lithium-ion battery anodes. J. Am. Chem. Soc. 2012, 134, 15010-15015.

[38] Al-Mamun, M.; Zhu, Z.; Yin, H.; Su, X.; Zhang, H.; Liu, P.; Yang, H.; Wang, D.; Tang, Z.; Wang, Y.; Zhao, H. The surface sulfur doping induced enhanced performance of cobalt catalysts in oxygen evolution reactions. Chem. Commun. 2016, 52, 9450-9453.

[39] Al-Mamun, M.; Su, X.; Zhang, H.; Yin, H.; Liu, P.; Yang, H.; Wang, D.; Tang, Z.; Wang, Y.; Zhao, H. Strongly coupled $\mathrm{CoCr}_{2} \mathrm{O}_{4} /$ carbon nanosheets as high performance electrocatalysts for oxygen evolution reaction. Small 2016, 12, 2866-2871.

[40] Cheng, Z.; Abernathy, H.; Liu, M. Raman spectroscopy of nickel sulfide $\mathrm{Ni}_{3} \mathrm{~S}_{2}$. J. Phys. Chem. C 2007, 111, 17997-18000.

[41] Zhu, J.; Li, Y.; Kang, S.; Wei, X. L.; Shen, P. K. One-step synthesis of $\mathrm{Ni}_{3} \mathrm{~S}_{2}$ nanoparticles wrapped with in situ generated nitrogen-self-doped graphene sheets with highly improved electrochemical properties in Li-ion batteries. J. Mater. Chem. A 2014, 2, 3142-3147.

[42] Haslam, G. E.; Chin, X. Y.; Burstein, G. T. Passivity and electrocatalysis of nanostructured nickel encapsulated in carbon. Phys. Chem. Chem. Phys 2011, 13, 12968-12974.

[43] Gao, S.; Liu, Y.; Li, G. D.; Guo, Y.; Zou, Y.; Zou, X. General urea-assisted synthesis of carbon-coated metal phosphide nanoparticles for efficient hydrogen evolution electrocatalysis. Electrochim. Acta 2016, 199, 99-107.

[44] Wu, Z. S.; Yang, S.; Sun, Y.; Parvez, K.; Feng, X.; Müllen, K. 3D Nitrogen-Doped Graphene Aerogel-Supported $\mathrm{Fe}_{3} \mathrm{O}_{4}$ Nanoparticles as Efficient Electrocatalysts for the Oxygen Reduction Reaction. J. Am. Chem. Soc. 2012, 134, 9082-9085.

[45] Zhu, T.; Zhu, L.; Wang, J.; Ho, G. W. In-situ chemical etching of tunable $3 \mathrm{D} \quad \mathrm{Ni}_{3} \mathrm{~S}_{2}$ superstructures for bifunctional electrocatalysts for overall water splitting. $J$. Mater. Chem. A 2016, 4, 13916-13922.

[46] Buckley, A. N.; Woods, R. Electrochemical and XPS studies of the surface oxidation of synthetic heazlewoodite $\left(\mathrm{Ni}_{3} \mathrm{~S}_{2}\right)$. J. Appl. Electrochem. 1991, 21, $575-582$.

[47] Al-Mamun, M.; Zhang, H.; Liu, P.; Wang, Y.; Cao, J.; Zhao, H. Directly hydrothermal growth of ultrathin $\mathrm{MoS}_{2}$ nanostructured films as high performance counter electrodes for dye-sensitised solar cells. RSC Adv. 2014, 4 , 21277-21283.

[48] Wang, Q.; Gao, R.; Li, J. Porous, self-supported $\mathrm{Ni}_{3} \mathrm{~S}_{2} /$ $\mathrm{Ni}$ nanoarchitectured electrode operating through efficient lithium-driven conversion reactions. Appl. Phys. Lett. 2007, 90, 143107.

[49] Tan, Z.; Liu, P.; Zhang, H.; Wang, Y.; Al-Mamun, M.; Yang, H. G.; Wang, D.; Tang, Z.; Zhao, H. An in situ vapour phase hydrothermal surface doping approach for fabrication of high performance $\mathrm{Co}_{3} \mathrm{O}_{4}$ electrocatalysts with an exceptionally high S-doped active surface. Chem. Commun. 2015, 51, 5695-5697.

[50] Al-Mamun, M.; Wang, Y.; Liu, P.; Zhong, Y. L.; Yin, H.; Su, X.; Zhang, H.; Yang, H.; Wang, D.; Tang, Z.; Zhao, H. One-step solid phase synthesis of a highly efficient and robust cobalt pentlandite electrocatalyst for the oxygen evolution reaction. J. Mater. Chem. A 2016, 4, 18314-18321.

[51] Yang, N.; Tang, C.; Wang, K.; Du, G.; Asiri, A. M.; Sun, $X$. Iron-doped nickel disulfide nanoarray: A highly efficient and stable electrocatalyst for water splitting. Nano Res. 2016, 9, 3346-3354.

[52] He, C.; Wu, S.; Zhao, N.; Shi, C.; Liu, E.; Li, J. Carbon-encapsulated $\mathrm{Fe}_{3} \mathrm{O}_{4}$ nanoparticles as a high-rate lithium ion battery anode material. ACS Nano 2013, 7, 4459-4469.

[53] Li, Y.; Zhang, H.; Wang, Y.; Liu, P.; Yang, H.; Yao, X.; Wang, D.; Tang, Z.; Zhao, H. A self-sponsored doping approach for controllable synthesis of $\mathrm{S}$ and $\mathrm{N}$ co-doped trimodal-porous structured graphitic carbon electrocatalysts. Energy Environ. Sci. 2014, 7, 3720-3726.

[54] Lee, Y.; Bae, S.; Jang, H.; Jang, S.; Zhu, S. E.; Sim, S. H.; Song, Y. I.; Hong, B. H.; Ahn, J. H. Wafer-scale synthesis 
and transfer of graphene films. Nano Lett. 2010, 10, 490-493.

[55] Homma, Y.; Kobayashi, Y.; Ogino, T.; Takagi, D.; Ito, R.; Jung, Y. J.; Ajayan, P. M. Role of transition metal catalysts in single-walled carbon nanotube growth in chemical vapor deposition. J. Phys. Chem. B 2003, 107, 12161-12164.

[56] Anna, M.; Albert, G. N.; Esko, I. K. The role of metal nanoparticles in the catalytic production of single-walled carbon nanotubes-a review. J. Phys.: Condens. Matter 2003, 15, S3011.

[57] Yokoyama, H.; Numakura, H.; Koiwa, M. The solubility and diffusion of carbon in palladium. Acta Mater. 1998, 46, 2823-2830.

[58] Fu, W.; Du, F. H.; Su, J.; Li, X. H.; Wei, X.; Ye, T. N.; Wang, K. X.; Chen, J. S. In situ catalytic growth of large-area multilayered graphene/ $\mathrm{MoS}_{2}$ heterostructures. Sci. Rep. 2014, 4, 4673.

[59] Chou, S. W.; Lin, J. Y. Cathodic deposition of flaky nickel sulfide nanostructure as an electroactive material for high-performance supercapacitors. J. Electrochem. Soc.
2013, 160, D178-D182.

[60] Xing, Z.; Chu, Q.; Ren, X.; Ge, C.; Qusti, A. H.; Asiri, A. M.; Al-Youbi, A. O.; Sun, X. $\mathrm{Ni}_{3} \mathrm{~S}_{2}$ coated $\mathrm{ZnO}$ array for high-performance supercapacitors. J. Power Sources 2014, 245, 463-467.

[61] Yang, Y.; Lun, Z.; Xia, G.; Zheng, F.; He, M.; Chen, Q. Non-precious alloy encapsulated in nitrogen-doped graphene layers derived from MOFs as an active and durable hydrogen evolution reaction catalyst. Energy Environ. Sci. 2015, 8, 3563-3571.

[62] Merki, D.; Vrubel, H.; Rovelli, L.; Fierro, S.; Hu, X. Fe, $\mathrm{Co}$, and $\mathrm{Ni}$ ions promote the catalytic activity of amorphous molybdenum sulfide films for hydrogen evolution. Chem. Sci. 2012, 3, 2515-2525.

[63] Gao, M.; Sheng, W.; Zhuang, Z.; Fang, Q.; Gu, S.; Jiang, J.; Yan, Y. Efficient Water Oxidation Using Nanostructured $\alpha$-Nickel-Hydroxide as an Electrocatalyst. J. Am. Chem. Soc. 2014, 136, 7077-7084. 


\section{Electronic Supplementary Material}

\section{Carbon Encapsulated Heazlewoodite Nanoparticles as Highly Efficient and Durable Electrocatalysts for Oxygen Evolution Reactions}

Mohammad Al-Mamun', Huajie Yin', Porun Liu', Xintai Su', ${ }^{1,2}$ Haimin Zhang', Huagui Yang', Dan Wang', Zhiyong Tang ${ }^{1}$, Yun Wang ${ }^{1}(\bowtie)$, Huijun Zhao ${ }^{1,3}(\bowtie)$

${ }^{1}$ Centre for Clean Environment and Energy, Griffith University, Gold Coast Campus QLD 4222, Australia

${ }^{2}$ Ministry Key Laboratory of Oil and Gas Fine Chemicals, College of Chemistry and Chemical Engineering, Xinjiang University, Urumqi 830046, China

${ }^{3}$ Centre for Environmental and Energy Nanomaterials, Institute of Solid State Physics, Chinese Academy of Sciences, Hefei 230031, China

Received: day month year / Revised: day month year / Accepted: day month year (automatically inserted by the publisher)

(C) Tsinghua University Press and Springer-Verlag Berlin Heidelberg 2011

Supporting information to DOI $10.1007 / \mathrm{s} 12274-* * * *_{-} * * * *_{-} *$ (automatically inserted by the publisher)

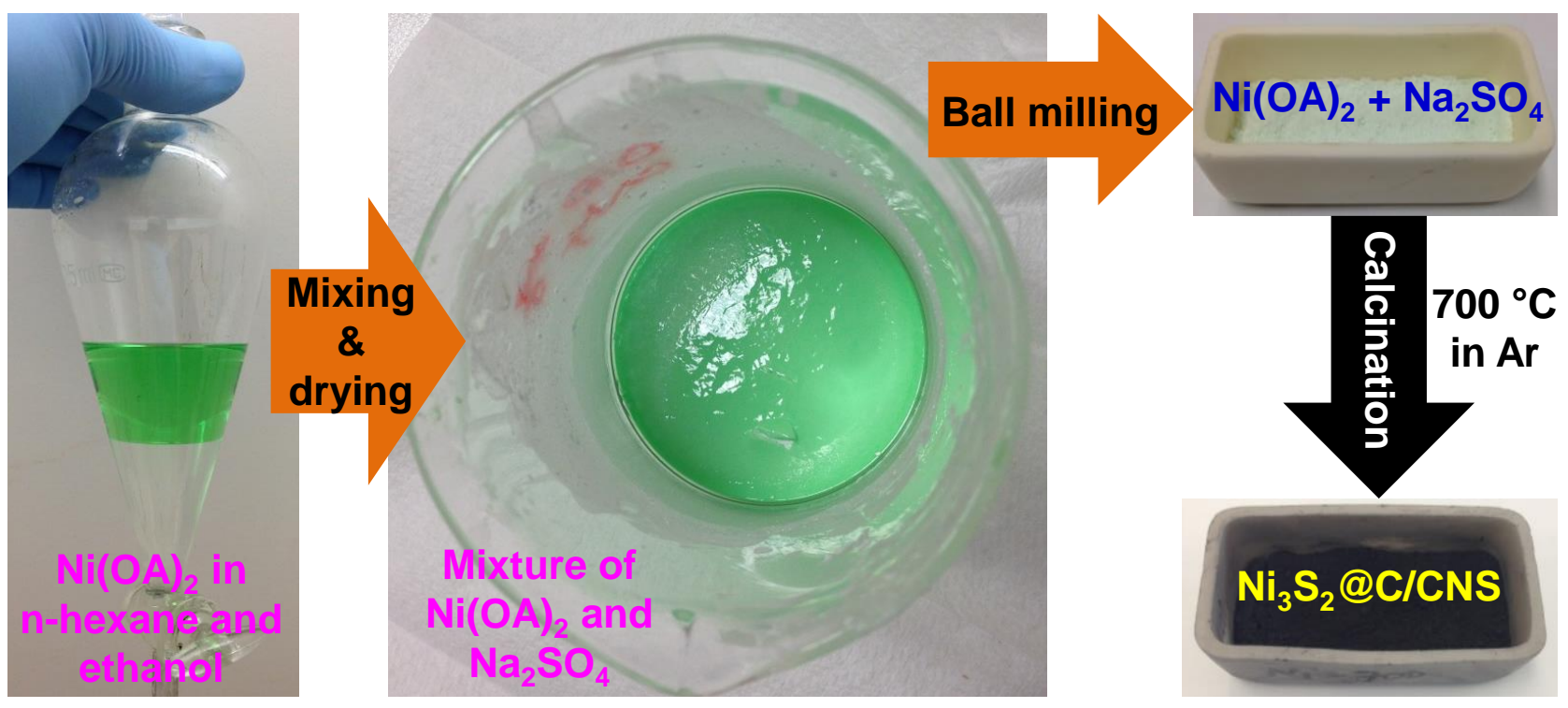

Fig. S-1 Digital photographs taken at the different stages of $\mathrm{Ni}_{3} \mathrm{~S}_{2} @ \mathrm{C} / \mathrm{CNS}$ nanocomposite fabrication. 

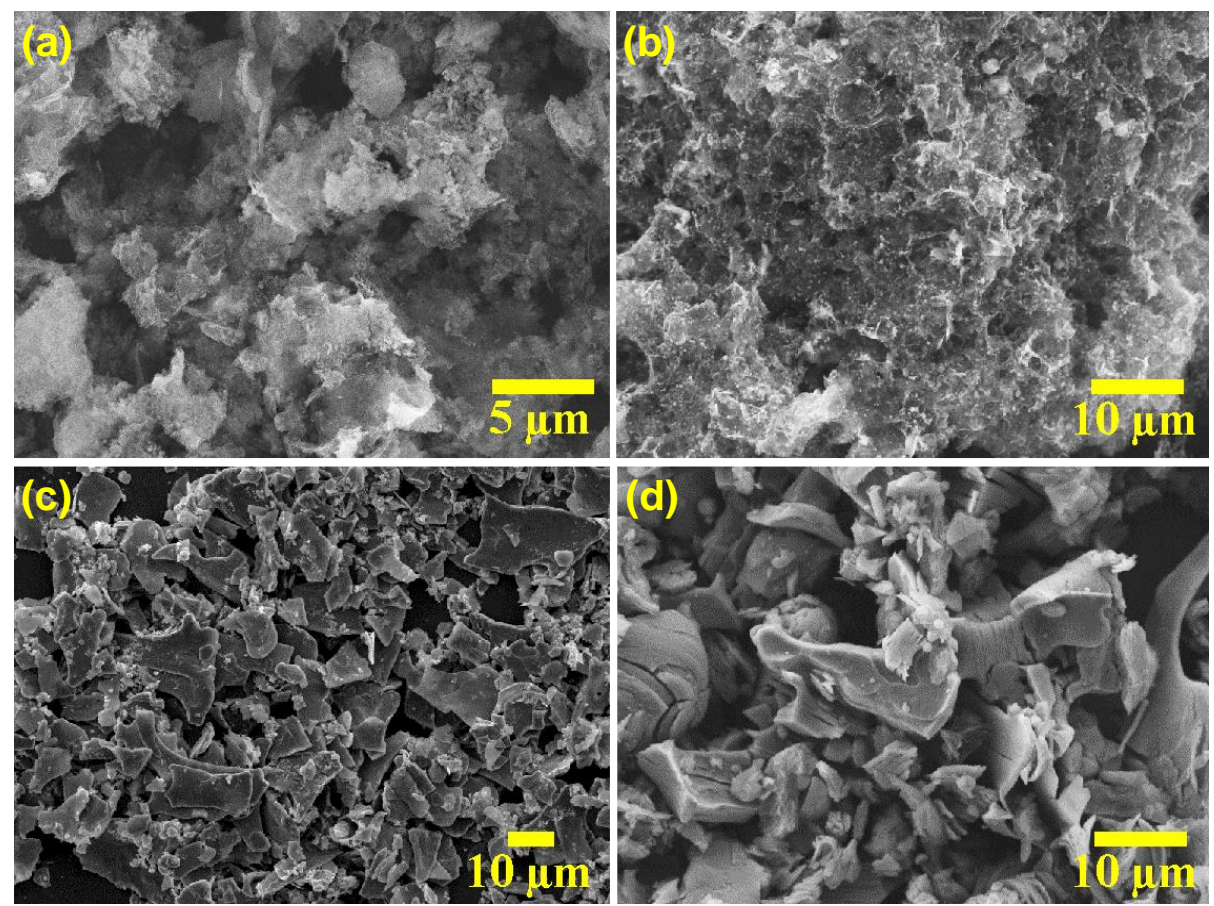

Fig. S-2 SEM images of the samples prepared at (a) 500, (b) 600, (c) 800 and (d) $900{ }^{\circ} \mathrm{C}$ under the same experimental conditions. 


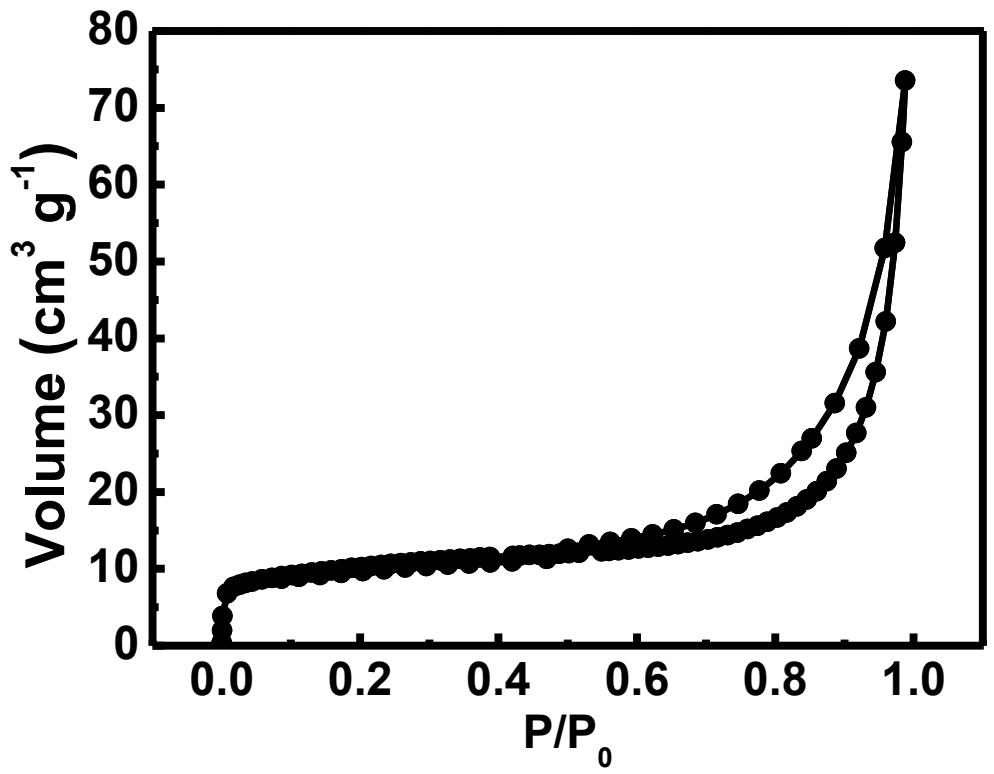

Fig. S-3 Nitrogen adsorption-desorption isotherm of $\mathrm{Ni}_{3} \mathrm{~S}_{2} @ \mathrm{C} / \mathrm{CNS}$ nanocomposite. 


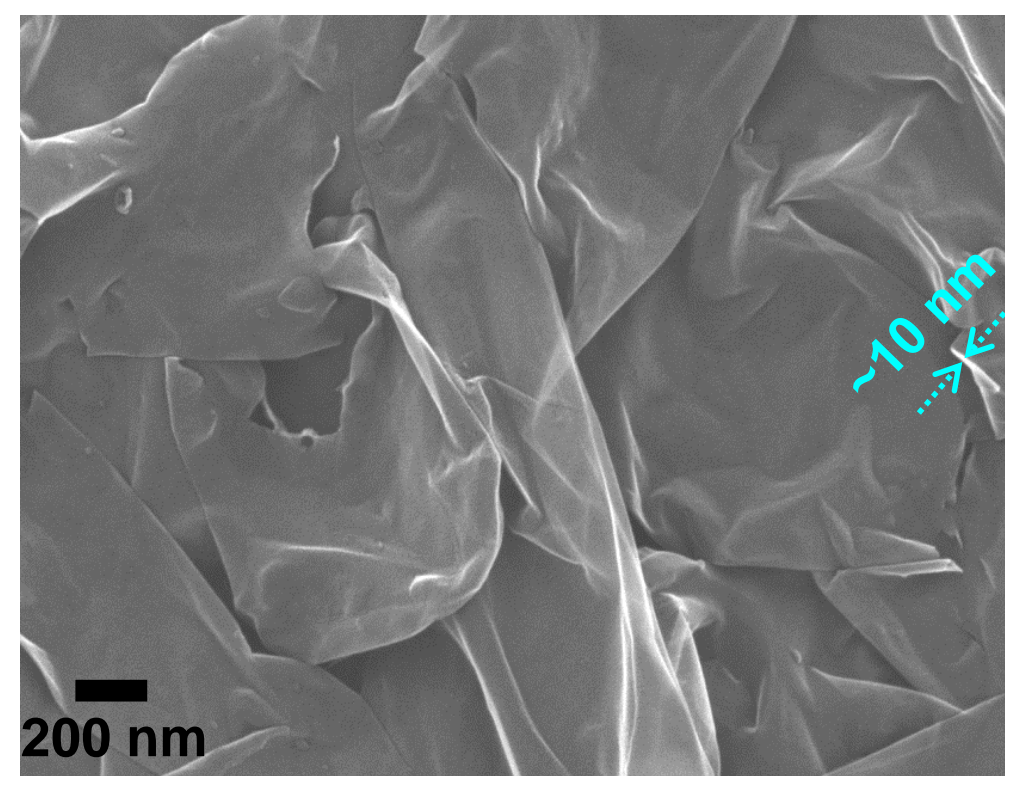

Fig. S-4 SEM image of the pristine CNS sample prepared at $700{ }^{\circ} \mathrm{C}$ displaying the thickness of $\sim 10$ $\mathrm{nm}$. 


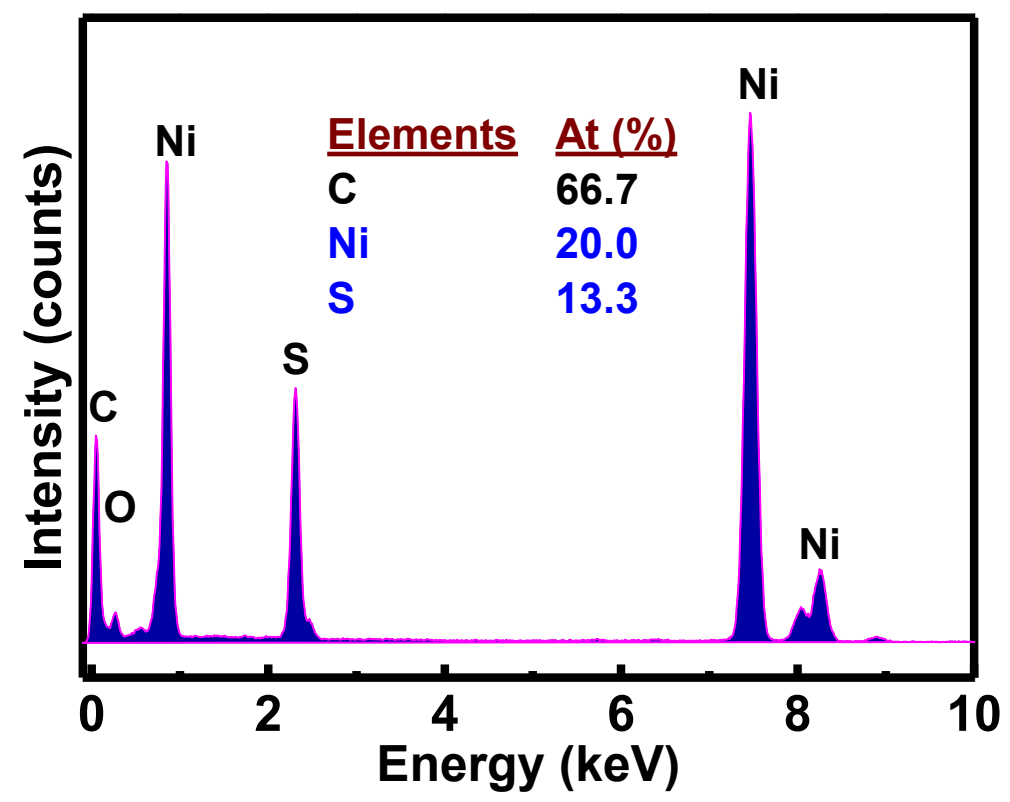

Fig. S-5 EDS results of the $\mathrm{Ni}_{3} \mathrm{~S}_{2} @ \mathrm{C} / \mathrm{CNS}$ nanocomposite. 


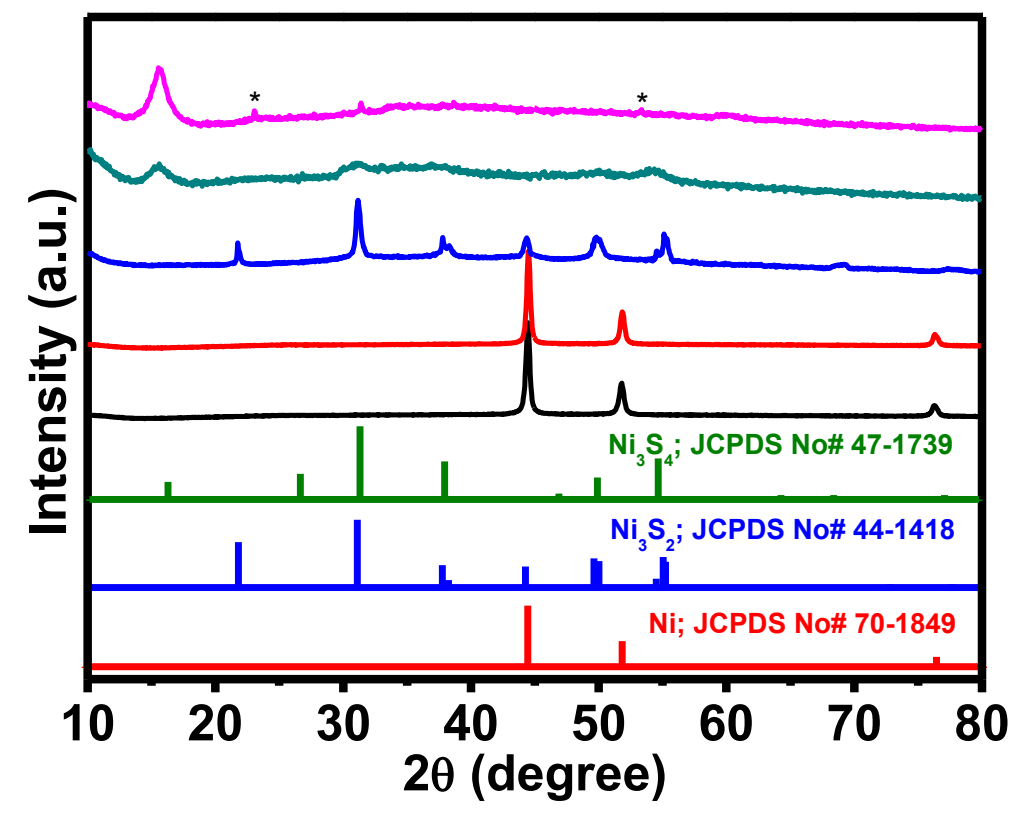

Fig. S-6 XRD pattern of the samples prepared at 500, 600, 700, 800 and $900{ }^{\circ} \mathrm{C}$ under Ar atmosphere. The peaks with "**" originated from the elemental sulfur species. 

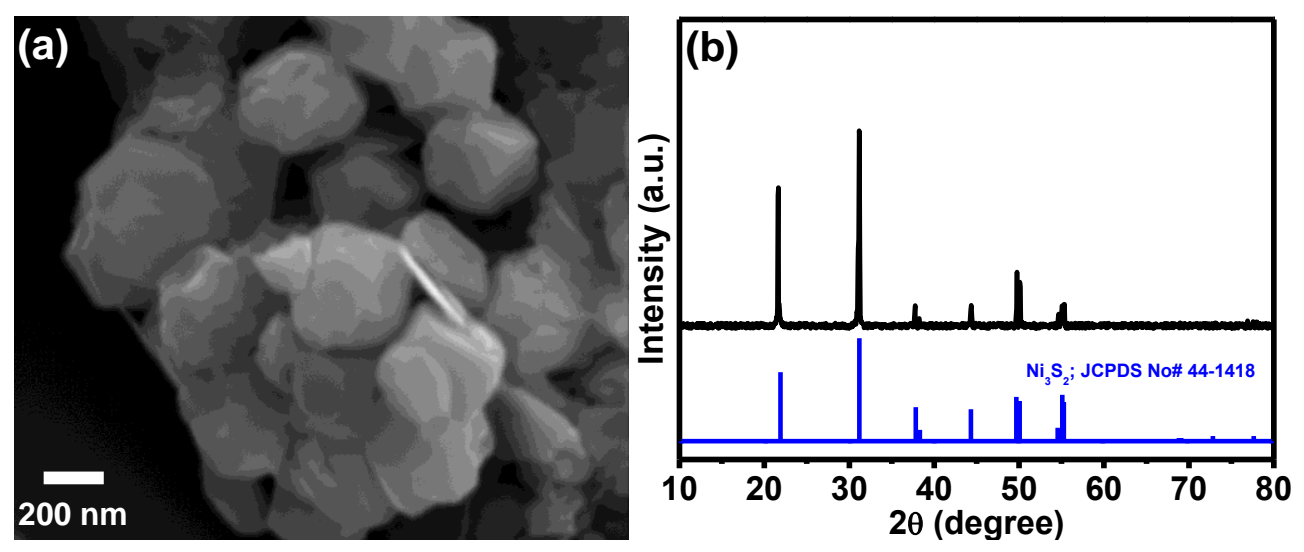

Fig. S-7 (a) SEM image and (b) XRD pattern of $\mathrm{Ni}_{3} \mathrm{~S}_{2}$ prepared by the hydrothermal method and calcinated at 700 ${ }^{\circ} \mathrm{C}$ under $\mathrm{Ar}$ atmosphere. 


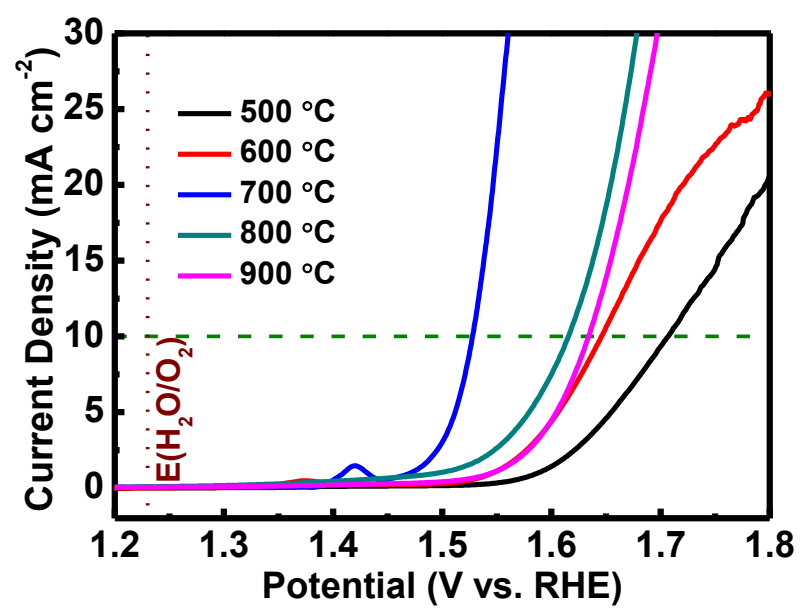

Fig. S-8 Polarisation curves of the samples prepared at different pyrolysis temperatures from $500-900{ }^{\circ} \mathrm{C}$. 

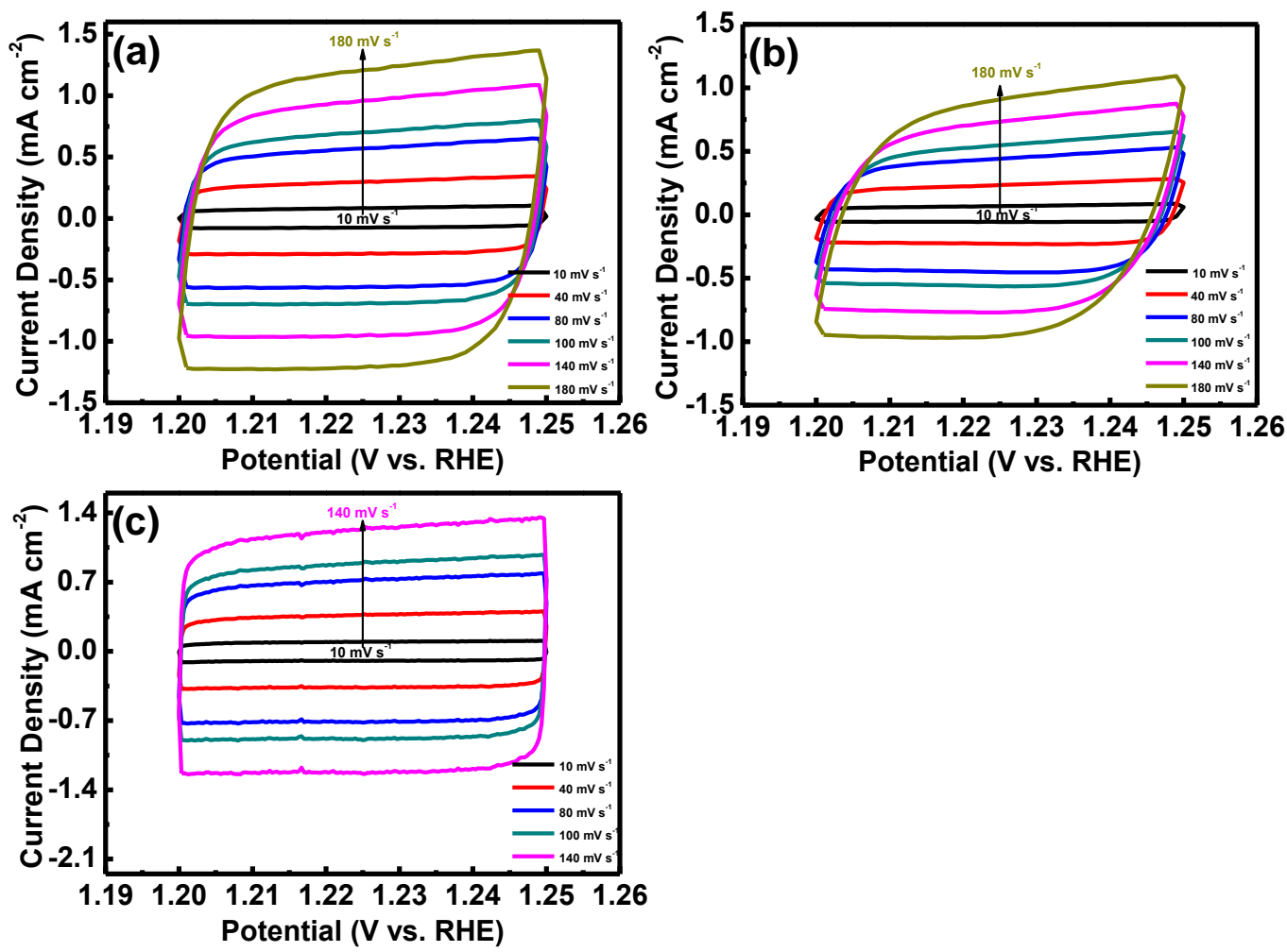

Fig. S-9 Cyclic voltammograms of (a) $\mathrm{Ni}_{3} \mathrm{~S}_{2} / \mathrm{CNS}$, (b) $\mathrm{Ni}_{3} \mathrm{~S}_{2}$ and (c) $\mathrm{RuO}_{2}$ at different scan rates from 10 to 180 $\mathrm{mV} \mathrm{s}^{-1}$ at the potential window of 1.20-1.25 V (vs. RHE). 
Table S1. A partial literature summary of the OER performances of nickel sulfide catalysts tested in $1.0 \mathrm{M} \mathrm{KOH}$ electrolyte.

\begin{tabular}{|c|c|c|c|c|c|c|}
\hline Catalysts & $\begin{array}{c}\eta @ 10 \mathrm{~mA} \\
\mathrm{~cm}^{-2}\end{array}$ & $\begin{array}{c}\text { Onset potential } \\
\text { (V vs. RHE) }\end{array}$ & $\begin{array}{l}\text { Tafel slope } \\
\left(\mathrm{mV} \operatorname{dec}^{-1}\right)\end{array}$ & $\begin{array}{c}\text { Mass loading } \\
\left(\mathrm{mg} \mathrm{cm}^{-2}\right)\end{array}$ & Substrate & Reference \\
\hline $\mathrm{Fe}_{0.1}-\mathrm{NiS}_{2} / \mathrm{Ti}$ & $231^{(\mathrm{a})}$ & $\sim 1.40$ & 43 & 0.8 & $\mathrm{Ti}$ & [1] \\
\hline $\mathrm{Fe}_{11.8 \%}-\mathrm{Ni}_{3} \mathrm{~S}_{2} / \mathrm{NF}$ & $253^{(a)}$ & $\sim 1.45$ & 65 & 7.9 & Ni foam & [2] \\
\hline $\mathrm{Ni}_{3} \mathrm{~S}_{2} / \mathrm{NF}$ & 260 & $\sim 1.35$ & - & 1.6 & $\mathrm{Ni}$ foam & [3] \\
\hline $\mathrm{Ni}_{3} \mathrm{~S}_{2} @ \mathrm{C} / \mathrm{CNS}$ & 298 & $\sim 1.46$ & 48.2 & 0.25 & GCE & This work \\
\hline $\mathrm{Ni}_{3} \mathrm{~S}_{2} / \mathrm{NF}$ & 300 & $\sim 1.50$ & 51 & - & Ni foam & [4] \\
\hline $\mathrm{MoO}_{\mathrm{x}} / \mathrm{Ni}_{3} \mathrm{~S}_{2}$ & $310^{(a)}$ & $\sim 1.45$ & 50 & 12 & $\mathrm{Ni}$ foam & [5] \\
\hline $\mathrm{NiS}$ & 320 & $\sim 1.48$ & - & 0.14 & FTO & [6] \\
\hline $\mathrm{NiS}$ & $\sim 335^{(\mathrm{a})}$ & $\sim 1.55$ & 89 & 43 & Ni foam & [7] \\
\hline $\mathrm{Ni}_{3} \mathrm{~S}_{2} @ \mathrm{Ni}$ & 340 & $\sim 1.50$ & 150 & - & Ni foam & [8] \\
\hline $\mathrm{Ni}_{9} \mathrm{~S}_{8}$ & $340^{(b)}$ & $\sim 1.50$ & 109.8 & 11.04 & Ni foam & [9] \\
\hline $\mathrm{NiS}_{\mathrm{x}}$ & 353 & $\sim 1.52$ & 56 & 0.5 & GCE & [10] \\
\hline $\mathrm{NiO}-\mathrm{NiS} / \mathrm{N}-\mathrm{C}$ & 374 & $\sim 1.56$ & 64.1 & 0.2 & CFP & {$[11]$} \\
\hline $\mathrm{Ni}_{3} \mathrm{~S}_{2} @ \mathrm{NC}$ & 390 & $\sim 1.50$ & 196 & 0.22 & GCE & [12] \\
\hline NiS@N/S-C & 417 & $\sim 1.54$ & 48 & 0.2 & CFP & {$[13]$} \\
\hline $\mathrm{NGC} @ \mathrm{Co}_{4} \mathrm{~S}_{3} / \mathrm{Ni}_{\mathrm{x}} \mathrm{S}_{6}$ & $420^{(\mathrm{c})}$ & $\sim 1.55$ & 37 & 0.28 & GCE & {$[14]$} \\
\hline
\end{tabular}

Corresponding overpotentials at (a) 100, (b) 30 and (c) $22.55 \mathrm{~mA} \mathrm{~cm}^{-2}$ 


\section{Supporting References}

[1] Yang, N.; Tang, C.; Wang, K.; Du, G.; Asiri, A. M.; Sun, X. Iron-doped nickel disulfide nanoarray: A highly efficient and stable electrocatalyst for water splitting. Nano Res. 2016, 9, 3346-3354.

[2] Cheng, N.; Liu, Q.; Asiri, A. M.; Xing, W.; Sun, X. A Fe-doped $\mathrm{Ni}_{3} \mathrm{~S}_{2}$ particle film as a high-efficiency robust oxygen evolution electrode with very high current density. J. Mater. Chem. A 2015, 3, 23207-23212.

[3] Feng, L. L.; Yu, G.; Wu, Y.; Li, G. D.; Li, H.; Sun, Y.; Asefa, T.; Chen, W.; Zou, X. High-index faceted $\mathrm{Ni}_{3} \mathrm{~S}_{2}$ nanosheet arrays as highly active and ultrastable electrocatalysts for water splitting. J. Am. Chem. Soc. 2015, 137, 14023-14026.

[4] Sivanantham, A.; Ganesan, P.; Shanmugam, S. Hierarchical $\mathrm{NiCo}_{2} \mathrm{~S}_{4}$ nanowire arrays supported on Ni foam: An efficient and durable bifunctional electrocatalyst for oxygen and hydrogen evolution reactions. Adv. Funct. Mat. 2016, 26, 4661-4672.

[5] Wu, Y.; Li, G. D.; Liu, Y.; Yang, L.; Lian, X.; Asefa, T.; Zou, X. Overall water splitting catalyzed efficiently by an ultrathin nanosheet-built, hollow $\mathrm{Ni}_{3} \mathrm{~S}_{2}$-based electrocatalyst. Adv. Funct. Mat. 2016, 26, 4839-4847.

[6] Mabayoje, O.; Shoola, A.; Wygant, B. R.; Mullins, C. B. The role of anions in metal chalcogenide oxygen evolution catalysis: electrodeposited thin films of nickel sulfide as "pre-catalysts". ACS Energy Lett. 2016, 1, 195-201.

[7] Zhu, W.; Yue, X.; Zhang, W.; Yu, S.; Zhang, Y.; Wang, J.; Wang, J. Nickel sulfide microsphere film on Ni foam as an efficient bifunctional electrocatalyst for overall water splitting. Chem. Commun. 2016, 52, 1486-1489.

[8] Zhu, T.; Zhu, L.; Wang, J.; Ho, G. W. In-situ chemical etching of tunable 3D Ni $\mathrm{Ni}_{2}$ superstructures for bifunctional electrocatalysts for overall water splitting. J. Mater. Chem. A 2016, 4, 13916-13922.

[9] Chen, G. F.; Ma, T. Y.; Liu, Z. Q.; Li, N.; Su, Y. Z.; Davey, K.; Qiao, S. Z. Efficient and stable bifunctional electrocatalysts $\mathrm{Ni} / \mathrm{Ni}_{\mathrm{x}} \mathrm{M}_{\mathrm{y}}(\mathrm{M}=\mathrm{P}, \mathrm{S})$ for overall water splitting. Adv. Funct. Mat. 2016, 26, 3314-3323.

[10] Li, H.; Shao, Y.; Su, Y.; Gao, Y.; Wang, X. Vapor-phase atomic layer deposition of nickel sulfide and its application for efficient oxygen-evolution electrocatalysis. Chem. Mater. 2016, 28, 1155-1164.

[11] Gao, M.; Yang, L.; Dai, B.; Guo, X.; Liu, Z.; Peng, B. A novel Ni-Schiff base complex derived electrocatalyst for oxygen evolution reaction. J. Solid State Electrochem. 2016, 20, 2737-2747.

[12] Barman, B. K.; Nanda, K. K. A noble and single source precursor for the synthesis of metal-rich sulphides embedded in an N-doped carbon framework for highly active OER electrocatalysts. Dalton Trans. 2016, 45, 6352-6356.

[13] Yang, L.; Gao, M.; Dai, B.; Guo, X.; Liu, Z.; Peng, B. An efficient NiS@N/S-C hybrid oxygen evolution electrocatalyst derived from metal-organic framework. Electrochim. Acta 2016, 191, 813-820.

[14] Ma, X. X.; He, X. Q. $\mathrm{Co}_{4} \mathrm{~S}_{3} / \mathrm{Ni}_{\mathrm{x}} \mathrm{S}_{6}(7 \geq \mathrm{x} \geq 6) / \mathrm{NiOOH}$ in-situ encapsulated carbon-based hybrid as a high-efficient oxygen electrode catalyst in alkaline media. Electrochim. Acta 2016, 213, 163-173. 